\title{
LA LINGÜÍSTICA CLÍNICA: TEORÍA Y PRÁCTICA
}

\author{
Elena Garayzábal-Heinze \\ Universidad Autónoma de Madrid. Grupo AETCOLI \\ elena.garayzabal@uam.es
}

\begin{abstract}
Resumen
La Lingüística Clínica es un nuevo ámbito de aplicación del conocimiento lingüístico. Su reconocimiento oficial en Reino Unido, en el año 1972, queda lejos de lo que en España hemos alcanzado y podemos esperar. En nuestro país los estudios de lingüística clínica, de base exclusivamente lingüística, aparecen tímidamente a partir de 1998. Son poco más de diez años los que esta aplicación convive con otras ramas de la lingüística externa, sin que se haya reconocido su importancia y su autonomía. Su reciente aparición en el campo de la Lingüística en España supone en primer lugar que (a) existan pocos lingüistas especializados en esta materia; (b) que no se hayan creado criterios linguísticos descriptivos y metodológicos suficientes y necesarios para la recogida y análisis de datos clínicos sobre la lengua española; (c) que el conocimiento lingüístico de los logopedas sea escaso y/o inadecuado para la práctica clínica, dada la escasez de lingüistas entendidos; (d) que el conocimiento de los pocos lingüistas entendidos en patologías del lenguaje que existen en nuestro país poco haya contribuido a la elaboración de herramientas que ayuden al logopeda a la evaluación e intervención con la finalidad de mejorar la comunicación, la lengua y el habla del paciente.

El lenguaje y sus alteraciones han sido estudiados desde muchos ámbitos disciplinarios. La Linguística Clínica no ha de ser ajena a las contribuciones que desde otras disciplinas se aportan a este conocimiento, pues avanzar en el desarrollo de esta nueva aplicación de la Lingüística supone saber cómo, qué y por qué puede alterarse la capacidad para la comuni-
\end{abstract}

\begin{abstract}
Clinical Linguistics is a new field of application of linguistics. Official recognition in the United Kingdom in 1972, is far from what we have reached in Spain and what we can expect to achieve. In our country clinical linguistics research, linguistically based, timidly appeared in 1998. It has been little more than ten years since this application of linguistics has co-existed with other branches of the external Linguistics, without having hadits importance and its autonomy recognized yet. Its recent appearance in the field of linguistics in Spain, means that (a) there are few specialized linguists in speech and language disorders; (b) no sufficient linguistic criteria have been established for the description and methodology necessary for the collection and analysis of clinical data in the Spanish language; (c) the linguistic knowledge of speech and language therapists is limited and / or inappropriate for clinical practice given the lack of linguists expert in this field, (d) the knowledge of the few linguists experienced in language pathologies that exist in our country has contributed little to the development of effective programs to help speech therapists to the assessment and intervention to improve communication, language and speech of the patient.

Language and its disorders have been studied from many disciplinary areas. Clinical linguistics should not be unconnected to contributions from other fields, because progress in the development of this new linguistic application involves knowing how, what and why the capacity for communication,
\end{abstract}


cación, la lengua y el habla; por este motivo debemos conectar el conocimiento lingüístico con el conocimiento procedente de la medicina, la biología, la psicología y la logopedia; ello nos permitirá comprender y saber cuáles pueden ser las posibles causas de un determinado comportamiento lingüístico (su etiología) y su frecuencia (su incidencia y epidemiología).

Aunque en el Reino Unido y en los Estados Unidos se ha ido avanzando en la investigación de las diferentes alteraciones del lenguaje, en España sigue habiendo una tendencia a describir aspectos lingüísticos relacionados con las afasias y a realizar estudios evolutivos del lenguaje con un desarrollo típico. Pese a que se realizan tímidas incursiones en otras alteraciones (TEL, TDAH, Trastornos de aprendizaje no verbal) muchas de las descripciones siguen estando principalmente en manos de los psicólogos.

Nos queda mucho por conseguir para poder equiparar nuestro trabajo al trabajo que se desarrolla fuera de nuestras fronteras, pero nuevos lingüistas están interesados en la los datos clínicos y poco a poco van surgiendo grupos de investigación centrados en este área de estudio.

PALABRAS CLAVE: Lingüística clínica, marcos teóricos, metodología, naturaleza de los datos lingüísticos, análisis, técnicas, herramientas y hablantes. language and speech can be altered; that is the reason why we should link the linguistic knowledge with the fields of medicine, genetics, psychology and speech therapy; this will allow us to understand and know what could be the possible causes of a particular linguistic behavior (its aetiology) and its frequency (incidence and epidemiology).

While in the United Kingdom and the United States research of the various disorders of language has been moving forward, in Spain there is still a tendency to describe linguistic aspects related to aphasia and evolutionary studies of language with a typical development. Although timid incursions are conducted in other disorders (SLI, ADHD, nonverbal learning disabilities) many of the descriptions are still in the hands of psychologists.

We have much to achieve in order to align our work to work done outside our borders, but new linguists are interested in clinical data and research groups focused on this area of study are slowly emerging.

KEY WORDS: Clinical linguistics, theoretical framework, methodology, linguistic data nature, analysis, techniques, tools, participants.

\section{Introducción}

Desde hace mucho tiempo ha existido un genuino interés por relacionar los aspectos del lenguaje con la mente, el cerebro y el pensamiento. Los estudios llevados a cabo por Broca, Wernicke y Lichtheim en la segunda mitad del siglo XIX fueron fundamentales para establecer conexiones entre el lenguaje y el cerebro a partir de dificultades en la codificación y decodificación del lenguaje manifestadas en diferentes pacientes. Mucho antes, Aristóteles y los pre-socráticos se plantearon las relaciones entre el lenguaje y el pensamiento y la exclusividad del sistema comunicativo del hombre frente a otros animales. En papiros anteriores a la era de Cristo, se refleja el interés por el lenguaje y las alteraciones del habla. Para un acercamiento histórico recomendamos las lecturas de Fernández (1998), Gutiérrez (1997) y Garayzábal (2006a). 
Las dificultades que algunos hablantes presentan con relación a la lengua, el habla o la comunicación, han sido foco de atención en diversos ámbitos y desde diferentes perspectivas, teórica y aplicada, y han suscitado cuestiones tan diversas como $i$ podemos explicar el desarrollo del lenguaje en el ser humano más allá de las adaptaciones evolutivas meramente físicas? ¿Cómo? ¿Qué mecanismos subyacen a esta capacidad universal? ¿Por qué tal complejidad de nuestro sistema comunicativo? ¿Cómo producimos y comprendemos la lengua? ¿Qué relaciones existen entre el lenguaje y el pensamiento? ¿y entre el lenguaje y el mundo? ¿Cómo está representado el lenguaje en nuestro cerebro?

El intento de responder a estas preguntas ha supuesto la descripción y análisis de problemas de la comunicación, lo que ha suscitado nuevas preguntas del tipo: cuando hay problemas en la comprensión o producción de la comunicación, lengua o habla, por ausencia, pérdida, desvío o retraso ¿qué es lo que se ha perdido y necesita recuperarse? ¿Respecto de qué patrón de la lengua hablamos de desvío? ¿Qué variación linguística tomamos como referencia? ¿Qué es lo que falta, formal y funcional, que debería estar? (Perkins y Howard, 1995).

A todas estas preguntas se ha intentado dar respuesta desde diferentes áreas y ámbitos de estudio dado el carácter multidimensional del estudio del sistema lingüístico del hombre.

1. Desde el ámbito médico

La Genética y la Fonogenética se interesan por los genes relacionados con el lenguaje.

La Neurología y la Neurolingüística se centran en el estudio de las áreas cerebrales implicadas en la producción y recepción del lenguaje.

La Otorrinolaringología y la Audiología prestan atención al canal de recepción y producción de los sonidos del habla.

2. Desde el ámbito psicológico

La Psicología Evolutiva se centra en los cambios que tienen lugar en las personas con el paso del tiempo y en las etapas del desarrollo en el niño.

La Psicolingüística analiza cualquier proceso que tenga que ver con la comunicación humana, mediante el uso del lenguaje atendiendo a los procesos de codificación y decodificación del lenguaje.

La Neuropsicología estudia los efectos que una lesión, daño o funcionamiento anómalo en las estructuras del sistema nervioso central causa sobre los procesos cognitivos.

3. Ámbito logopédico o terapéutico:

La Logopedia o Fonoaudiología se centra en la prevención, diagnóstico y tratamiento o intervención integral de los trastornos de la comunicación humana. 


\section{4. Ámbito educativo}

Magisterio en Audición y Lenguaje en el que cobra interés la educación de los niños con graves problemas de audición, sordos o que no saben hablar.

Magisterio en Educación Especial es la disciplina que forma a profesionales encargados de potenciar y asegurar el cumplimiento del principio de equiparación de oportunidades de aquellos niños, niñas y jóvenes que presentan necesidades educativas especiales derivadas o no de una discapacidad en todos los niveles y modalidades del sistema escolar, con el propósito de asegurarles aprendizajes de calidad.

\section{5. Ámbito psicopedagógico}

La psicopedagogía consiste en el apoyo y la orientación a la acción educativa, posibilitando criterios de mejora en el diseño, desarrollo, innovación y evaluación de los procesos educativos entre los que el lenguaje y la comunicación constituyen una piedra angular.

\section{6. Ámbito filosófico}

La Filosofía del Lenguaje se interesa por cuestiones como las relaciones entre el lenguaje y el mundo, esto es, entre lo lingüístico y lo extralingüístico, o entre el lenguaje y el pensamiento, el estudio del origen del lenguaje, la simbolización del lenguaje (lenguaje artificial) y, sobre todo, la actividad lingüística en su globalidad y la semántica.

\section{7. Ámbito antropológico}

La Antropología Lingüística se ocupa del estudio de la diversidad de lenguas habladas por las sociedades humanas y cómo se relacionan los usos lingüísticos con las características culturales básicas de dichas sociedades.

\section{8. Ámbito lingüístico}

La Lingüística, principalmente centrada en el análisis del sistema lingüístico, con sus formas, niveles y funciones.

La Paleontología Lingüística que pretende clarificar la prehistoria de grupos lingüísticos.

La Paleoantropolingüística centra su interés en los orígenes del lenguaje.

La Etnolingüística estudia cómo diferentes culturas organizan y categorizan distintos dominios del conocimiento.

La Etnografía de la Comunicación aborda la descripción de las normas, explícitas o implícitas, de los aspectos verbales y no verbales de la interacción comunicativa.

La Biolingüística estudia el lenguaje natural desde una perspectiva biológica y evolutiva.

La Lingüística Aplicada a la Didáctica de Lenguas se interesa por los procesos de aprendizaje y adquisición de segundas lenguas y su enseñanza. 
La Lingüística Clínica intenta aplicar la teoría lingüística al ámbito de las patologías del habla, lengua y comunicación tanto en niños como adultos, a la vez que aplica los conocimientos acerca del lenguaje patológico para refinar y modificar las teorías lingüísticas.

Todas las disciplinas mencionadas están estrechamente relacionadas, tanto que muchas de ellas se confunden entre sí:

- Antropología lingüística y etnografía lingüística

- Fonogenética, biolingüística y paleoantropolingüística

- Biolingüística, psicología evolutiva y paleoantropolingüística

- Lingüística Clínica y logopedia

Hay quienes llegan a establecer relaciones de equivalencia entre ellas y el hecho es que, aunque dos áreas de investigación compartan un mismo objeto de análisis, no es razón suficiente para considerarlas una misma disciplina o que una se subsuma en otra (Codesido, 1998). De este desconcierto entre disciplinas surgen también colateralmente confusiones terminológicas y de delimitación de fronteras disciplinarias que resultan en un mal entendido intrusismo entre disciplinas, en lugar de abogar por un enriquecimiento a partir de la interdisciplinariedad que proporciona un abanico más amplio y comprensible del lenguaje y sus manifestaciones particulares e idiosincrásicas de los hablantes y para el entendimiento de la cognición humana en general:

El manejo de un mismo término en diferentes marcos teóricos conlleva cargas conceptuales diferentes en cada caso, pero no sólo eso, sino que si además sumamos la polivalencia significativa inherente al propio término, el resultado no es otro que un mar de ambigüedades que conducen a la pérdida del valor de la noción (Fernández, 1984).

\section{El lenguaje}

El lenguaje es una capacidad humana específica que se manifiesta en forma de conducta observable consistente en signos verbales o de otro tipo, como los gestuales y tiene una realidad mental, fisiológica, psicológica y biológica (Alonso-Cortés, 2002); además, se trata de un fenómeno social, cultural e histórico. Se trata seguramente de facultad humana que más diversidad y matices presenta y de ahí que las conexiones interdisciplinarias sean muchas.

El lenguaje es un sistema representacional y comunicativo que está relacionado con el funcionamiento del cerebro. La capacidad para usar este sistema parece requerir de una organización específica de los mecanismos del sistema nervioso que se considera única en el ser humano. 
Los estudios de Broca, a finales del siglo XIX, mostraron que las funciones del lenguaje se producen básicamente en un hemisferio del cerebro. Aunque no queda claro en cuál de los hemisferios (derecho o izquierdo) se produce la dominancia cerebral para el lenguaje, parece que el hemisferio izquierdo es dominante para la comprensión y producción de los aspectos más formales del lenguaje (sonidos, morfemas y aspectos estructurales de la sintaxis), mientras que el hemisferio derecho sería dominante para aspectos más funcionales (comprensión y producción de elementos paralingüísticos del habla y aspectos extralingüísticos).

\begin{tabular}{|c|c|}
\hline Hemisferio izquierdo & Hemisferio derecho \\
\hline Procesado verbal & Procesado visual, cinético y emocional \\
Memoria auditiva verbal & Memoria auditiva no verbal \\
Pensamiento abstracto & Pensamiento concreto \\
Tiempo & Espacio \\
Secuencias & Atención difusa \\
Atención focalizada & Atención visual \\
Atención auditiva & Música \\
Ritmo & Síntesis \\
Análisis & Emoción, procesos inmediatos \\
Lógica, procesos elaborados & Organización automática e involuntaria \\
Organización consciente & Intuición \\
Razón & Sentido del absurdo \\
Sentido de la organización & Preparación a la creatividad. \\
Preparación a la memoria & \\
\hline
\end{tabular}

CUADRO 1. Especialización funcional hemisférica del cerebro según Bryan, 1994. (Apud. Garayzábal, 2006a).

Independientemente de si la dominancia cerebral para el lenguaje está situada en uno u otro hemisferio, sí están determinadas qué regiones de la corteza cerebral son importantes para el lenguaje.

En términos generales, y sin entrar en gran detalle, dado que no es el propósito de este trabajo, podemos señalar que las estructuras corticales comprometidas en el habla y el lenguaje son el área de Broca está involucrada en la programación motora del habla, en ella se produce la producción del habla fluida y bien articulada; está situada en la circunvolución frontal inferior del lóbulo frontal. En el lóbulo temporal, se encuentra la circunvolución de Heschl, área auditiva primaria importante para la recepción de estímulos auditivos y junto a la que se encuentra el área de Wernicke 
donde se produce la comprensión del habla. En el lóbulo parietal se encuentra el área somatosensorial primaria donde se producen los procesos de elaboración de sensaciones. En el lóbulo occipital se localiza el área primaria para la recepción de estímulos visuales. Además de las estructuras corticales, existen estructuras subcorticales de tanta o más importancia que las corticales con grandes implicaciones para el habla y la comunicación (Love y Webb, 1986; Caplan, 1987; Obler y Gjerlow, 1999; Marantz et al. 2000). Cualquier lesión tanto a nivel cortical como subcortical ocasiona importantes problemas a la hora de poder producir y comprender el lenguaje limitando de forma importante la comunicación.

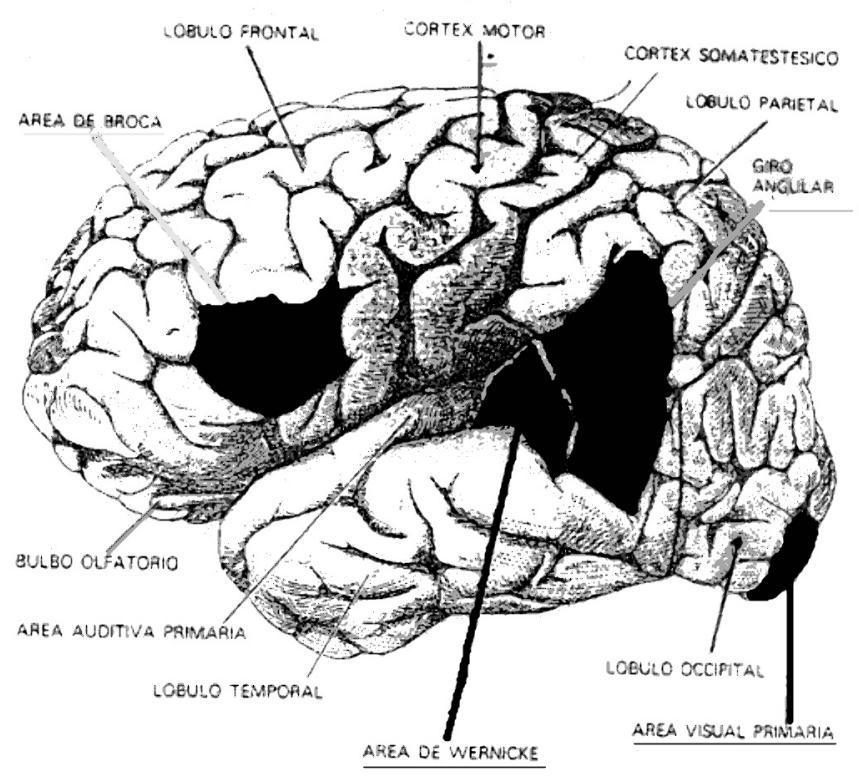

FIGURA 2. Lenguaje y cerebro.

El lenguaje es un proceso cognitivo complejo que gira, por un lado, en torno al proceso de comprensión, definido como la capacidad de entender e interpretar el lenguaje hablado y en el que intervienen factores cognitivos (atención, memoria, percepción) involucrados para llegar a la interpretación de unidades macro y microestructurales. Por otro lado, la producción, referida al proceso de programación y realización de la acción de hablar. Las figuras del oyente y el hablante cobran gran relevancia. 


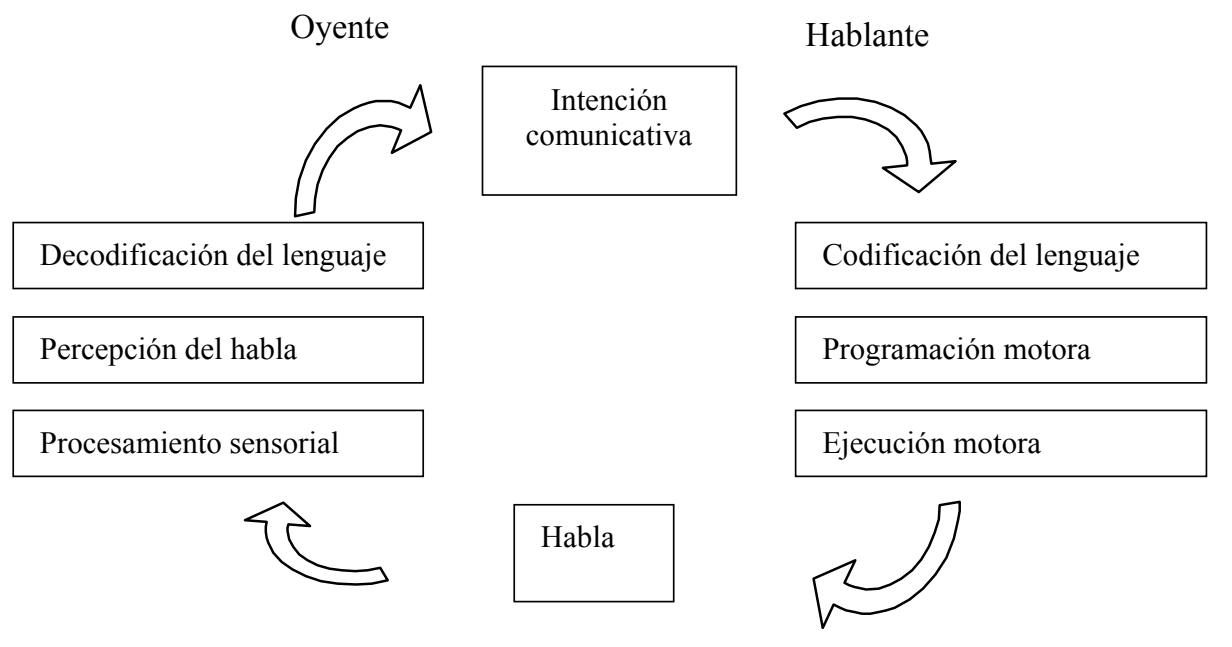

CUADRO 3. El proceso de comunicación (Cummings, 2008).

Las habilidades que subyacen al lenguaje y que permiten la comunicación e interacción social entre los hablantes tiene que ver con la pragmática, la semántica y el léxico, la sintaxis, la morfología, la fonología y la fonética.

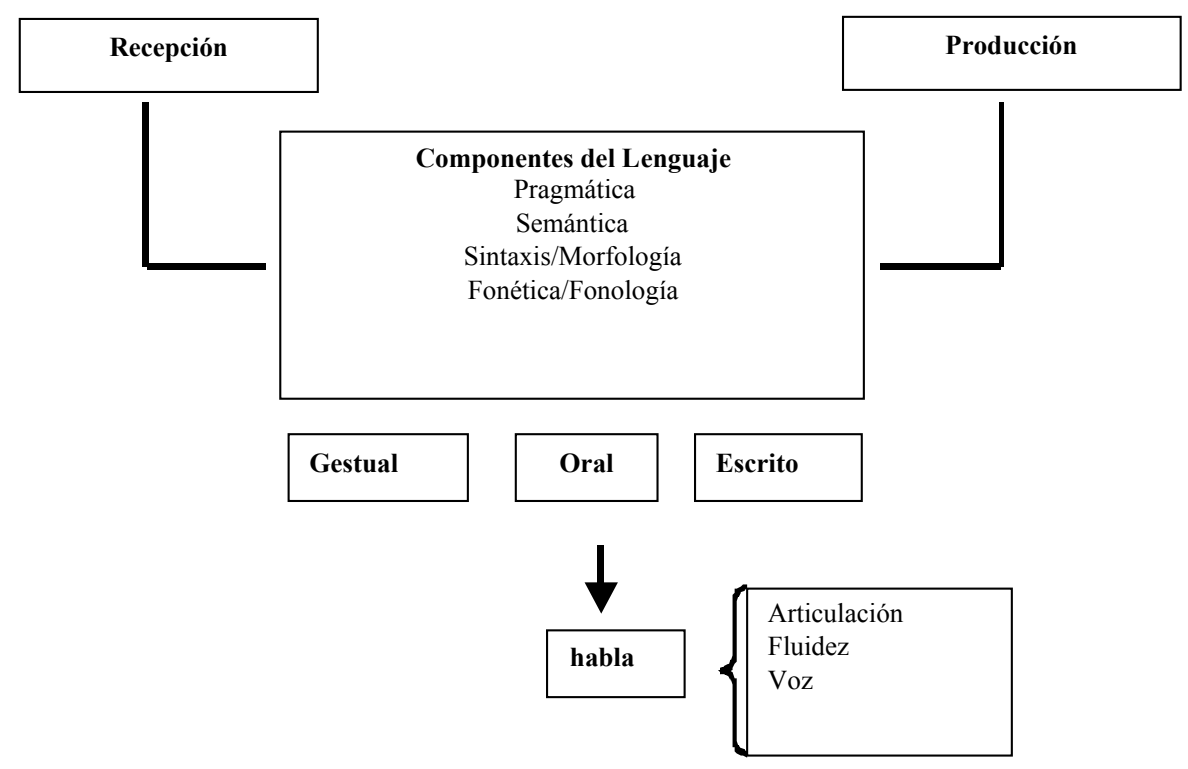

CUADRO 4: El lenguaje: Habilidades subyacentes 
Las modalidades en que puede presentarse el lenguaje son diversas: la modalidad gestual, oral y escrita.

A) La modalidad gestual está representada por aquellos gestos, naturales o arbitrarios, que permiten complementar la modalidad oral o sustituirla.

B) La modalidad oral está representada por los sonidos que constituyen el habla. El habla es una cadena de sonidos discretos que se enlazan unos con otros para construir emisiones mayores con significado (sílabas, palabras, frases, oraciones, discursos).

b.1. laijademiermanasellamaolibia

b.2. lai-ja-de-mier-ma-na-se-lla-mao-li-bia

b.3. la-i-ja-de-mi-er-ma-na -se-lla-ma-o-li-bia

b.4. la -ija-de-mi-ermana -se-llama-olibia

b.5. la ija-de mi ermana-se llama olibia

b.6. la ija de mi ermana-se llama olibia

b.7. la ija de mi ermana se llama olibia

C) La modalidad escrita. Se trata de un sistema arbitrario de representación de la lengua oral que puede ser más o menos transparente en las diferentes lenguas. En el caso del español el sistema de representación escrita de la lengua oral presenta poca opacidad, esto es, hay una traducción o correspondencia grafema-fonema bastante clara y directa, mientras que esto no se produce, por ejemplo, en los sistemas de escritura del inglés o el francés, poco transparentes en esta correspondencia. La modalidad escrita de la lengua requiere del adecuado desarrollo de la conciencia fonológica, sintáctica y semántica.

La comunicación constituye un aparente sólido edificio en el que se alojan la lengua y el habla. Este edificio tiene una arquitectura compleja cuyas vigas soportan la pragmática, la semántica, el léxico, la gramática y el sistema fónico que, a su vez, se subsumen en una compleja estructura final que descansa en la comprensión y producción del lenguaje.

Cuando observamos, analizamos y evaluamos el lenguaje, lo hacemos partiendo de los diferentes niveles lingüísticos. Para llegar a una mejor comprensión del lenguaje como sistema de comunicación y sus manifestaciones solemos disociar las habilidades y procesos, pero no debemos perder de vista los diferentes interfaces entre niveles y procesos. De no ser así, podríamos no reconocer al elefante y fragmentaríamos la realidad de los hechos hasta tal punto que no reconoceríamos lo que estamos analizando (al elefante) ${ }^{1}$, por lo que no podríamos integrar nuestras

1 Parábola del elefante. Una antigua parábola hindú dice que una vez seis hombres ciegos querían saber cómo era un elefante. El primer hombre ciego alargó sus manos y tocó el inmenso lado del animal. "Este elefante es como una pared alta y fuerte," dijo el ciego.

El segundo hombre, situado cerca de la cabeza del elefante, puso sus manos en uno de los largos y afilados colmillos. “¿Una pared? ¡No! Yo diría que se parece más a una lanza” 
observaciones en un marco más amplio y comprehensivo que unificara los diferentes tipos de datos procedentes de otras áreas y que permitiera el desarrollo y enriquecimiento de un debate teórico y empírico que pusiera en relación la lingüística con otros campos de la ciencia cognitiva.

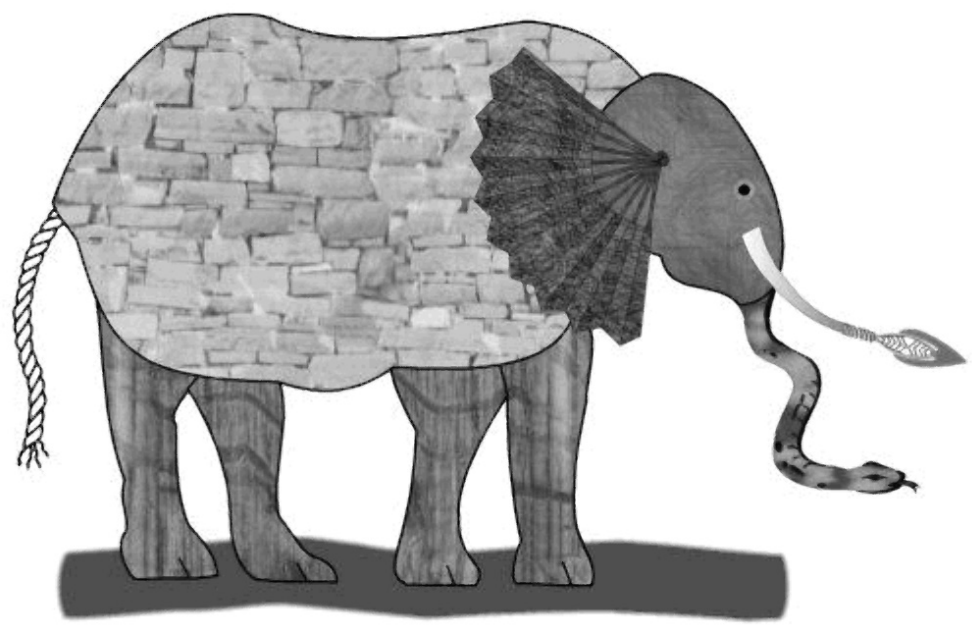

FIGURA 5. ¿Visión integrada de un problema? (http://www.vidadigital.net/blog/2005/04/07/)

\section{La Lingüística Clínica}

La aparición del lenguaje oral en el hombre es tan antigua como sus dificultades para comunicar. Desde hace más de 30.000 años que esta habilidad surgió en el hombre. Desconocemos muchos aspectos de estos estadios iniciales en la prehistoria lingüística del ser humano y más incógnitas todavía suscitan sus alteraciones.

El tercer hombre se abrazó una de las patas del elefante y dijo: "Estoy seguro que el elefante es como un árbol."

El cuarto hombre tocó la oreja del elefante. "En mi opinión, el elefante se parece mucho a un abanico."

El quinto hombre, que había cogido la cola del animal, observó:. "Me parece que estáis todos equivocados, el elefante es como una soga."

El elefante, harto de que lo tocaran, empujó suavemente con la trompa al sexto ciego. Éste, asustado, se apartó lejos del elefante y dijo temeroso:"¡El elefante es en realidad una culebra muy grande!".

Contentos de saber cada uno lo que para ellos era un elefante, se fueron sin haber unificado sus percepciones, sin saber realmente cómo era un elefante. 
Las diferentes teorías en torno a la filogénesis y ontogénesis de esta facultad específica del ser humano para el lenguaje, su descripción y diferentes planteamientos y acercamientos a su estudio han hecho correr ríos de tinta, han enfrentado posturas y han acercado otras y parece que, aunque siguen existiendo numerosos aspectos sin resolver, hay muchos que parecen estar asumidos dentro de la comunidad científica dedicada a su estudio. Sin embargo, el estudio de las limitaciones para el habla, la lengua y la comunicación sigue suponiendo una gran incógnita, por ser un estudio complicado y resbaladizo, principalmente debido a la perspectiva de estudio adoptada, dado que el fenómeno del lenguaje y sus patologías es variado y variable, su metodología diversa, las bases o marcos teóricos de los que se parte para su estudio son de una gran amplitud y los objetivos que se persiguen de una gran heterogeneidad.

La medicina y la psicología han sido las disciplinas en torno a las que se ha desarrollado la investigación en las patologías del lenguaje. Sin embargo, desde hace poco tiempo una nueva disciplina ha emergido para completar la investigación y descripción de las alteraciones lingüísticas; se trata de un nuevo campo de estudio que descansa sobre los pilares del conocimiento lingüístico aplicado a las dificultades de la lengua, el habla y la comunicación y que debe constituirse y consolidarse como una alternativa científica en el estudio de estos problemas a la hora de dar cuenta de ciertos hechos lingüísticos que desde otros campos resulta difícil de explicar; "linguistics is only one of a whole range of disciplines which contribute to the understanding and management of linguistic disability" (Crystal, 1981: 7).

La Lingüística Clínica es una subdisciplina de la Lingüística que tiene que ver con aspectos del habla y las patologías lingüísticas, alteraciones del lenguaje o el déficit lingüístico. Se trata de un campo relativamente joven que surge en los años 70, momento en que se reconoce la importancia del conocimiento lingüístico en el estudio de los trastornos de la comunicación. Tal reconocimiento se refuerza en el año 1972 cuando en Reino Unido la Lingüística Clínica se consolida como una asignatura obligatoria de cualquier programa de logopedia, por lo que obtiene un estatus oficial reconocido, en buena parte debido al informe Quirk elaborado por el Comité de Investigación Gubernamental sobre Servicios de Terapia del Habla (Government Committee of Inquiry into Speech Therapy Services) y dirigido por Randolf Quirk ${ }^{2}$. Esta idónea situación está lejos de producirse en España donde la Lingüística Clínica no tiene visos de constituirse como una aplicación autónoma de la Lingüística, aunque constituya un área de su conocimiento (Garayzábal, 2004).

2 En el informe se apoyaba a la lingüística como conocimiento básico en la formación de los logopedas quienes "should be made more aware of and be better equipped to understand and apply the results of such research [by linguists, audiologists, neurologists, psychologists and others]. HMSO (1972). 
El campo de la Lingüística Clínica se ha ido expandiendo poco a poco, pero, como recuerda Cummings (2008), la lingüística clínica ha sido un área de investigación importante mucho antes de su reconocimiento oficial en Reino Unido, y podemos remontarnos a 1925 con la fundación de la Asociación Americana para el Lenguaje y la Audición (ASHA -American Speech language-Hearing Association) y el Real Colegio del Terapeutas del Habla y Lenguaje (The Royal College of Speech and Language Therapists) fundado en 1945:

One of the origins of Bristish speech therapy in the 1920s and 1930s was phonetics [...] in particular one line of development was associated with the British School of Phonetics lead by Professor Daniel Jones at University College London. This association continued after the establishment of the profession and the College of Speech Therapist, in 1947/8, through the training schools. Grunwell (1988: 36-37).

David Crystal fue el primero en acuñar el término de la nueva disciplina emergente en su libro Clinical Linguistics (1981) que definió como "the application of linguistic science to the study of communication disability, as encountered in clinical situations" (Crystal, 1981: 1). Años más tarde revisó su definición y la reformuló:

Clinical lingüistics is the application of the theories, methods and findings of linguistics (including phonetics) to the study of those situations where language handicaps are diagnosed and treated [...] For me Clinical Linguistics is first a foremost branch of applied linguistics, though one about which it is difficult to generalize, perhaps because there are so few clinical linguists around. Crystal (1984: 30-31).

La definición ha sido levemente modificada en momentos posteriores; así, Ball y Kent (1987) resaltaron la importancia de incluir los datos clínicos para la evaluación de la actuación lingüística y para contribuir a una mayor precisión de las teorías lingüísticas y, en caso de ser necesario, su modificación.

De nuevo Crystal aporta una nueva definición de este área de estudio y la redefine como un campo interdisciplinario basado en la "aplicación de las teorías y métodos lingüísticos al análisis de los desórdenes del lenguaje hablado, escrito o sígnico" (1994: 412).

En 1995 Perkins y Howard abogaron por una definición más comprehensiva "[Clinical Linguistics is] the application of theoretical and descriptive linguistics to speech and language pathology and remediation. Perkins y Howard (1995: 11).

Ya en el siglo XXI, Cummings adopta la siguiente definición:

Clinical linguistics is the study of numerous ways in which the unique human capacity can be disordered. This includes "language disorders", as standarly 
conceived. However, it also includes ddisorders that result from disruption to the wider processes of languafe transmitiion and reception and disorders of the vegetative functions that are an evolutionary precursor to language. Most notably, it includes all the disorders that are encountered by speech and language therapists across a range of clinical contexts. Cummings (2008: 1).

La Lingüística Clínica, en mi opinión, se constituye y define como una nueva perspectiva de estudio caracterizada por adoptar un enfoque integrador y multidisciplinar que intenta dar cuenta de los problemas que conciernen a la forma y función comunicativa del ser humano y que impiden o limitan su interacción con los demás, por inhibición, ausencia, distorsión, divergencia o deterioro de su habilidad lingüística, toda vez que debe aportar herramientas lingüísticas para su evaluación, proporcionar pautas de interpretación de los datos clínicos y facilitar materiales a los profesionales responsables de la rehabilitación de los trastornos del habla, la lengua y la comunicación. "Clinical Linguistics may be one of the foundation-stones of speech pathology, but is no more than that" (Crystal, 1981: 205).

El objetivo de un lingüista no es la rehabilitación del paciente, pues ésta es competencia del logopeda. El lingüista analiza y describe un problema para ayudar a su mejora:

La labor del lingüista se observa ante casos como el de una confusión de los sonidos $[\mathrm{t}]$ y $[\mathrm{s}][\ldots]$ donde habrá que decidir primero si se trata de un mero rasgo dialectal o de un trastorno, y si es esto último, habrá que ver si se trata sólo de un déficit de pronunciación [...] o si además nos encontramos con problemas de concordancia, en cuyo caso también se vería afectado el nivel gramatical. Garayzábal y Otero (2005: 178).

Estas definiciones dejan patente el camino de ida y vuelta desde la linguística a las patologías del lenguaje y de éstas de nuevo a la lingüística. De este modo, se han ido incorporando técnicas de análisis y diferentes metodologías para el desarrollo de estudios de investigación encuadrados en diferentes modelos teóricos y se han modificado y readaptado teorías lingüísticas.

A todas luces la Linguística Clínica debe suponer un soporte básico de todos aquellos especialistas que trabajen con personas con problemas de lenguaje, su labor debe estar orientada al compromiso terapéutico, de tal modo que desde el conocimiento lingüístico y su comprensión los logopedas, y también lingüistas, puedan desarrollar un amplio abanico de herramientas terapéuticas orientadas a la rehabilitación de la comunicación, la lengua y el habla (Brumfitt, 2004). En este sentido, tanto la teoría como la práctica se convierten en un todo integrado para el desarrollo de un programa de intervención terapéutica de base lingüística.

Una vez definida esta subdisciplina lingüística, el paso siguiente es determinar a quién se considera un lingüista clínico y cuál ha de ser su formación. La persona 
dedicada a la LC debe tener una base formativa amplia y sólida en teoría lingüística. Sin embargo, un mero conocimiento de los aspectos de la teoría lingüística no es suficiente para ser un lingüista clínico, sino además tener inquietud e interés específico por los trastornos de deterioro, ausencia, desvío, distorsión o retraso de las habilidades lingüísticas. En España este interés ha devenido en un autodidactismo por la dificultad en formarse en otras áreas, principalmente biosanitarias, y pocos son los que han completado su perfil con cursillos de formación en lenguaje y audición o incluso estudios de logopedia. También que desde otros ámbitos la necesidad de conocer más sobre el lenguaje para aplicar sus conocimientos a la rehabilitación de los trastornos del lenguaje supone que maestros especialistas en audición y lenguaje y logopedas sientan la necesidad de una formación más sólida en cuanto a conocimiento lingüístico. Por ello, como bien señalan Perkins y Howard (1995) podría existir un "espectro del lingüista clínico" en cuyos extremos se situaría por un lado el lingüista académico con interés en los trastornos de la comunicación, y por el otro el logopeda. Sin embargo, entre un extremo y otro se encuentran profesionales de diferente formación que hacen Lingüística Clínica y no todos tienen formación lingüística suficiente. Este amplio espectro de profesionales se justifica a partir del estudio de una capacidad tan multidimensional como es lenguaje, como se vio más arriba. La valía de estos profesionales vendrá avalada por su dominio del conocimiento lingüístico y la capacidad de relacionar este conocimiento con las observaciones sobre el desempeño lingüístico de los pacientes y la puesta en práctica de programas de rehabilitación de base lingüística.

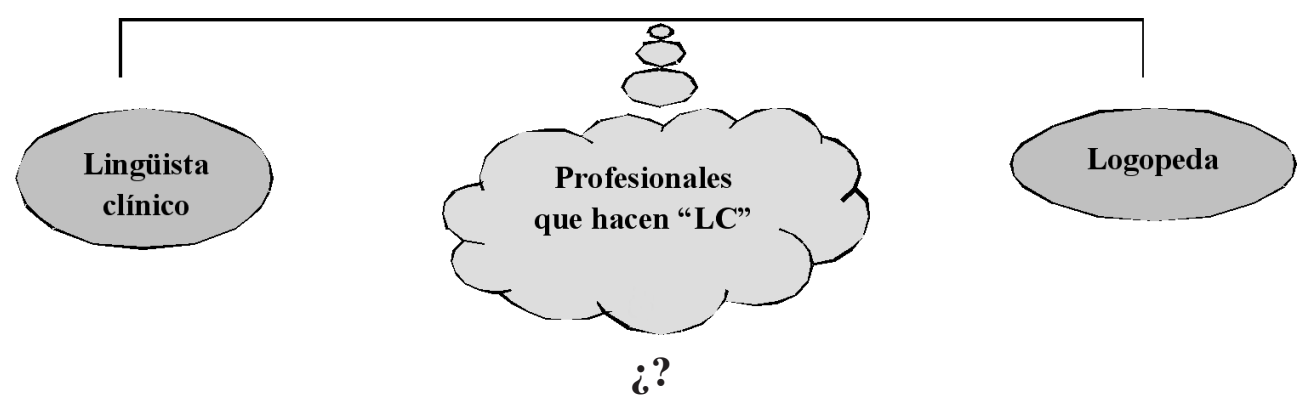

FIGURA 6. El lingüista clínico.

\section{Conocimiento lingüístico y marcos teóricos}

Desde la propia Lingüística las alteraciones del lenguaje se contemplan a partir los diferentes acercamientos y marcos teóricos. Es importante tener en cuenta las 
palabras de Perkins y Howard cuando señalan la existencia de dos problemas importantes en la aplicación de la teoría de la lingüística a la descripción de los hechos que afectan a la complejidad de forma y función de los hechos lingüísticos:

(1) Which theory and model to choose from a range of possible contenders, and (2) the fact that theories are constantly changing. With regard to (1) we can do no more than keep abreast of theoretical developments in our area of interest -certainly no easy task - [...] The difficulties inherent in problem (2) are apparent in the large back catalogue of articles which made use of theoretical frameworks that are now superseded or outmoded. This does not mean that such articles no longer have anything of value to offer, but they are certainly lesslike to be consulted now". Perkins y Howard (1995: 12).

La Lingüística clínica carece de construcción teórica propia, sin embargo, es necesario partir de alguna base teórica que nos posibilite plantear el problema, cómo poder analizarlo y cómo llegar a determinadas conclusiones. No es preciso que la base teórica de la que partamos sea muy conocida o escasa siempre y cuando nos permita dar cuenta de nuestros objetivos y llevar a cabo la descripción, análisis y explicación de nuestros datos. Asimismo, habremos de ser conscientes de que los análisis de los datos clínicos contribuyen en gran medida a la teoría lingüística del lenguaje en general falsándola, contrastándola, ampliándola, ayudando a la clasificación de los datos lingüísticos y su explicación, en definitiva, enriqueciéndola.

Para evaluar las habilidades lingüísticas del paciente respecto a la comprensión y producción del lenguaje es importante partir de un modelo lingüístico que posibilitará aplicar el conocimiento teórico para interpretar los datos clínicos con el fin de enfocar posteriormente la terapia. El conocimiento lingüístico teórico posibilitará identificar los problemas de lenguaje que el paciente muestra en términos de adecuación o inadecuación lingüística e informatividad e interacción comunicativa. Por otro lado, el conocimiento lingüístico facilitará y ayudará al profesional a interpretar e integrar la información holísticamente, de manera que puedan establecerse relaciones significativas de causa-efecto entre los datos, más allá de los meros datos aislados. Garman y Edwards (1995) llamaron la atención sobre la escasa deseabilidad de separar rígidamente por niveles los datos lingüísticos, dado que es poco frecuente que un déficit lingüístico respete fronteras lingüísticas.

Un sólido conocimiento de la teoría lingüística y su aplicación a situaciones en las que el lenguaje se vea comprometido permitirá tomar decisiones de forma racional y no aleatoria sobre la evaluación y la intervención, y permitirá valorar la pertinencia o no de las pruebas estandarizadas de evaluación de la habilidad lingüística y de los datos obtenidos (Bray et al, 2006; Garayzábal y Capó, 2006; Moreno-Torres, 2004). 
¿A qué llamamos conocimiento lingüístico orientado a los profesionales que trabajan con personas con alteraciones del lenguaje?

Los conocimientos que un especialista que interviene en problemas de la comunicación, lengua y habla debe poseer se relacionan con los diferentes niveles de análisis lingüístico: fónico, gramatical, léxico-semántico y pragmático, cuyo análisis y evaluación permiten crear un perfil lingüístico del paciente a partir de una muestra representativa de su habla en la que se reflejarán las habilidades y las dificultades. Sin embargo, el conocimiento lingüístico también le permitirá adoptar una visión crítica en torno a la validez y representatividad de teorías y modelos que le permitan explicar los datos.

\subsection{El nivel fónico}

El nivel fónico se refiere a los sonidos de la lengua y lo conforman la fonética y la fonología. La primera estudia los sonidos independientemente de la función que cumplen en el sistema lingüístico. La fonología, sin embargo, estudia la función de los sonidos dentro del sistema, la capacidad que tienen para diferenciar palabras.

El lingüista clínico debe transmitir a los profesionales de la rehabilitación que un problema en el nivel fonético puede relacionarse con puntos y modos de articulación incorrectos, por ejemplo la pronunciación de la consonante ápico-alveolar vibrante múltiple sonora $[r]$, que con frecuencia en los niños españoles pasa a ser velar, fricativo, sordo $[R]$. Este conocimiento fonético de puntos y modos de articulación resulta de gran relevancia a la hora de rehabilitar una dislalia. Ante un caso como este, el terapeuta debería saber que una parte importante de la terapia consistirá en ir avanzando el punto de articulación y proporcionar sonidos sustitutos que coincidan en el punto de articulación, p.e. la [1]. En un momento posterior deberá conseguir hacer vibrar al ápice de la lengua.

Sin embargo, los aspectos fonéticos no se reducen al nivel del segmento, sino que pueden abarcar a varios segmentos, esto es, es suprasegmental y tiene que ver con la información prosódica centrada en la longitud, acento, tono, cualidad de la voz, volumen y ritmo. Una afectación en el nivel suprasegmental ocasiona alteraciones prosódicas, muy llamativas, por ejemplo, en los lesionados del hemisferio derecho.

Para la trascripción fonética del habla del paciente se utiliza el Alfabeto Fonético Internacional (IPA, 1999) o los signos fonéticos publicados por la Revista de Filología Española (1915) y Navarro (1966-67). Coloma (2002: 181-182) presenta una tabla de equiparación de los signos fónicos entre el AFI y la RFE que resulta útil. Además de estos sistema de trascripción, existe una ampliación del API para el habla patológica (Duckworth et al, 1990).

Respecto a los aspectos fonológicos, es importante que el logopeda observe si los sonidos utilizados interfieren o no en la comprensión del habla. Se trata de ana- 
lizar si la producción de los sonidos se corresponde con los sonidos de la lengua. En el caso de pacientes con problemas en este nivel se valorarían aspectos relacionados con las omisiones (natual por natural) sustituciones (toche por coche) distorsiones, adiciones (ritímica por rítmica), asimilaciones (pediódico por periódico), inversiones (golbo por globo), reducciones (libo por libro).

Un sólido conocimiento lingüístico del logopeda le permite observar también si existe un patrón común de procesos fonológicos que se repiten, como por ejemplo, si el sonido [b] se convierte en [p] y ocurre lo mismo con el sonido [d] que se convierte en $[\mathrm{t}]$ y $[\mathrm{g}]$ se pronuncia $[\mathrm{k}]$ el logopeda debería concluir que el paciente en cuestión lleva a cabo un proceso de ensordecimiento de las oclusivas.

Desde la fonología tampoco se analizan los sonidos por unidades, sino también sus combinaciones (fonotaxis), en este caso el logopeda deberá saber qué combinaciones son posibles en la lengua en cuestión, cual es la frecuencia de esas combinaciones, cuales son los errores más comunes cometidos en la población infantil que nos sirvan de referencia para analizar los errores del paciente.

Un aspecto no desarrollado hasta el momento y que cobra importancia tiene que ver con los patrones de adquisición de los sonidos y sus combinaciones (adquisición del lenguaje) y su correspondencia con las frecuencias reales de esos patrones en la lengua. Las etapas en el desarrollo del lenguaje del niño y los datos lingüísticos no se corresponden. Existe una importante descompensación entre lo que ocurre en el proceso de adquisición (patrones de adquisición) y lo que ocurre con la propia lengua (patrones lingüísticos). Procesos fonológicos como la elisión, la frecuencia de sonidos en una lengua y sus agrupaciones en una lengua dada se pasan por alto desde la perspectiva evolutiva. Estos datos de carácter lingüístico son relevantes y significativos (Garayzábal 2006b).

Importante también es hacer una aclaración. Es habitual en la bibliografía anglosajona encontrarnos con una dicotomía interesante en relación con la Lingüística y la fonética, ejemplos claros son el título de la revista de referencia en el ámbito de la lingüística clínica Clinical lingüistics and Phonetics, o el título del diccionario de David Cristal (1980) A dictionary of Linguistics and Phonetics, y así muchos títulos más. ¿Significa esto que la fonética no forma parte del estudio de la lingüística? Crystal dilucida esta cuestión que parece solventada y aceptada en el mundo anglosajón, pero no ha terminado de permeabilizar en España y, tal vez, con razón:

¿Es la fonética una disciplina autónoma o debe considerarse una rama de la lingüística? Por lo que se refiere a los métodos, es ciertamente muy distinta y la investigación fonética del tipo (a) (fonética articulatoria) ${ }^{3}[\ldots]$ no tiene nada que

3 El paréntesis es nuestro. La fonética articulatoria estudia cómo los órganos vocales producen los sonidos del habla. 
ver con los objetivos del análisis lingüístico. No obstante, la investigación fonética del tipo (b) (fonética acústica) ${ }^{4}$ forma parte claramente de la investigación lingüística. Crystal (2000: 239).

En España la fonética no tiene una entidad tan marcada. Es una cuestión de quién y cómo se marcan las fronteras. En nuestro país las fronteras las constituye la propia lingüística y la fonética está integrada en ella. Por otro lado, la cita de Crystal puede ser muy cuestionable, dado que hay quienes piensan que precisamente es la fonética articulatoria la más susceptible de análisis lingüístico que la acústica.

\subsection{Nivel gramatical}

El nivel gramatical engloba dos tipos de conocimiento lingüístico, el nivel morfológico y el nivel sintáctico. Ambos niveles tienen que ver con la estructura ya sea de la palabra o de la oración.

La observación y análisis del nivel gramatical tendrá en cuenta aspectos relacionados con la flexión, formación de palabras, concordancias, estructura de frases, orden de los elementos, complejidad gramatical y tipo de estructuras dominantes, errores comunes en el nivel gramatical y errores no apropiados del lenguaje patológico (Codesido, 2006).

Es importante en este punto los aspectos relacionados con la morfología flexiva y las lenguas. El terapeuta del lenguaje debe saber que cuanto más flexiva sea una lengua, mayores posibilidades de error y dificultades existirán en un trastornos de lenguaje. El español es una lengua muy flexiva, frente a, por ejemplo, el inglés que, aun siendo flexiva, lo es mucho menos que el español. De este modo los errores de concordancia de género en español son mayores de lo que lo serán para el inglés, lo mismo ocurre con el verbo, extremadamente flexivo en español, frente al verbo en inglés. La distinción entre flexión regular e irregular está disociada en los trastornos del lenguaje y puede servir de criterio diagnóstico para algunas alteraciones como pueden ser las afasias (Penke, 2008).

Respecto a la estructura sintáctica, y si seguimos a Ball (1992), habría tres niveles de análisis. El primero de ellos relacionado con la función de la oración (pregunta, exclamación, enunciación). En segundo lugar, dirigiríamos la atención al nivel interno de la oración, esto es, cuáles son las unidades que la componen, si son unidades variables (nombre, adjetivo, artículos, determinantes) o invariables (conjunciones, adverbios, preposiciones) y el orden en que aparecen. Las preposiciones y las conjunciones son elementos relacionales que contraen su significado en

4 El paréntesis es nuestro. La fonética acústica estudia las propiedades físicas de los sonidos del habla en su transmisión entre la boca y el oído. 
función del contexto lingüístico, la preposición $a$ puede tener muchos significados: voy a casa, dáselo a María; lo mismo ocurre con en: está en casa, está en la mesa. La omisión o uso indebido de estos elementos puede ocasionar sentidos raros o llegar a incongruencias significativas: me levanto tarde pero temprano; subió hacia su habitación; se cortó en el cuchillo. El orden en que se disponen las unidades en la oración es determinante dado que, por ejemplo, en varios tipos de afasias o en el TEL se producen muchos agramatismos.

En tercer lugar, prestaríamos atención al nivel funcional de la frase, es decir, las funciones que tienen los elementos que forman la estructura (sujeto, verbo, objeto). Deberemos fijarnos en qué elementos que deben aparecer están o no; por ejemplo, si el paciente utiliza el verbo dar, éste precisa de un sujeto, un complemento directo y otro indirecto (alguien DA algo a alguien), son elementos obligatorios que rige el verbo, en cuanto falta uno la oración está incompleta.

\subsection{Nivel léxico-semántico}

Se centra en el vocabulario y en los aspectos del significado de las palabras. El estudio del vocabulario, tanto pasivo (comprensión de vocabulario) como activo (vocabulario que producimos) es una importante herramienta dado que desde una perspectiva evolutiva el léxico es un fuerte predictor del desarrollo tardío del lenguaje y de la severidad de la alteración lingüística.

Por otro lado, las palabras tienen un significado conceptual básico (semántica léxica) que se modifica cuando la misma palabra se integra en un contexto gramatical (semántica gramatical) o en un contexto comunicativo (semántica pragmática).

En términos generales, los aspectos léxico-semánticos tienen en cuenta la frecuencia de aparición de las palabras, su categorización y clasificación, dobles significados.

Nociones como papeles temáticos cobran gran importancia en lingüística clínica, dado que permiten analizar significados relacionales y establecer relaciones entre la semántica y la estructura sintáctica, lo que en situaciones clínicas permite hablar de inversión de errores y omisión de argumentos (Black y Chiat, 2008):

What is necessary is a lexical semantic representation that explicity encodes properties of events, including their "subeventual" structure -a desideratum recognized by the now common use of the term "event structure" to refer to such representations. Levin y Rappaport (2005: 238).

También la semántica componencial da cuenta de aspectos relativos al análisis de los trastornos del lenguaje. Está descrito que determinadas patologías lingüísticas (afasia y dislexia adquirida) presentan grandes dificultades con los conceptos abstractos, tanto para comprenderlos como para utilizarlos, mientras que los conceptos concretos no suponen ninguna dificultad (Cummings, 2008). 
En el marco de las alteraciones del lenguaje es relevante observar y analizar el uso que el paciente hace de las palabras, si éstas se utilizan correcta o incorrectamente, o no del todo apropiadamente en el contexto lingüístico en que aparecen (me desplomó la ola; evacuó el vaso en el fregadero), si logra acceder o no a la palabra (anomia), qué recursos utiliza cuando no logra acceder a la palabra (¿parafasias o circunloquios?), qué tipo de categorizaciones realiza el niño o el paciente, qué relaciones semánticas se establecen; dominancia en el uso de hiper o hipónimos (me comí una fruta, me comí una manzana, me comí una Granny Smith), qué tipo de errores semánticos comete ¿congruentes o incongruentes? (unto la mantequilla con el calcetín, las ideas verde incoloras duermen furiosamente). Existen numerosas alteraciones en las que el aspecto semántico del lenguaje se ve afectado (afasias, demencias tipo Alzheimer, por ejemplo) y puede producirse una pérdida selectiva o un trastorno más general de este componente.

\subsection{Nivel pragmático}

En este punto el análisis está directamente relacionado con el uso que se hace del lenguaje, cómo lo utilizamos para establecer relaciones de interacción adecuadas con los demás, tiene que ver con el significado más allá del código lingüístico; así, se deberá prestar atención a aspectos de la cohesión, coherencia y relevancia del mensaje, el principio de cooperación, iniciación del habla, actos de habla, la toma de turnos, las pausas, interrupciones, elementos extralingüísticos (i.e. aproximación excesiva al interlocutor, problemas en identificar los estados emocionales en las expresiones faciales, contacto ocular, entre otros) y paralingüísticos (i.e. patrones anormales de vocalización, volumen inadecuado a la situación comunicativa; problemas en utilizar e identificar patrones prosódicos del habla, etc.), cambio de temas, temas recurrentes, inferencias realizadas, comprensión y producción de ironías, frases hechas, humor, entre otros. Todos estos aspectos cuando no están adecuadamente desarrollados o preservados conducen a importantes problemas de comunicación y socialización (Garayzábal, 2005; Gallardo, 2006; Perkins, 2007).

Un aspecto importante a la hora de analizar los diferentes niveles es considerar dónde establecemos la línea de normalidad y comportamiento lingüístico inapropiado, de manera que se pueda identificar y caracterizar modos de habla, lengua y comunicación anómalos o atípicos. Por ello los perfiles lingüísticos, que se comentarán más abajo, cobran especial relevancia para poder establecer los límites de adecuación o inadecuación del comportamiento lingüístico.

Además del conocimiento relativo a los diferentes niveles de análisis lingüístico, constituye parte de esta formación conocer los puntos fuertes y débiles de cada marco teórico a la hora de determinar y analizar los datos. 
La realidad es que a partir de la perspectiva de la Lingüística Clínica se puede dar cuenta de los datos clínicos desde diversas aproximaciones teóricas y metodológicas que permiten contemplar, examinar y reflexionar sobre los datos más allá de los diferentes marcos teóricos. Los acercamientos lingüísticos teóricos al estudio del lenguaje se mueven hoy en día entre el formalismo y el funcionalismo (cognitivismo). Sin embargo, se recuperan cada vez más otros modelos o teorías lingüísticas considerados obsoletos o superados, pero que dan perfecta cuenta de los hechos lingüísticos patológicos.

Los estudios del siglo XIX que relacionaban lenguaje y cerebro fueron tomados en consideración desde la linguística y llevaron a Saussure, por ejemplo, a introducir nociones como las de lengua y habla y a diferenciarlas y discutirlas en sus dimensiones metodológicas y ontológicas (Fava, 2002). También dentro del modelo estructuralista, los estudios de Jakobson sobre la generalización de la adquisición y pérdida del componente gramatical han sido considerados de gran relevancia más allá del marco estrictamente lingüístico. Menos importancia se ha otorgado a las teorías del estructuralista francés Benveniste (1977) con relación a la capacidad intersubjetiva y las huellas lingüísticas concretas que nos permiten a los seres humanos de atribuir pensamientos e intenciones a otras personas en el habla de una persona y que desde la psicología recibe el nombre de Teoría de la Mente. Gallardo parte de la teoría pragmática de la enunciación de este lingüista para aplicarla al Trastorno por déficit de la Atención e Hiperactividad TDAH). Según esta teoría:

en cada acto de habla los hablantes nos adueñamos de la lengua para construir nuestros mensajes (nuestros 'enunciados'), pero dejando siempre en ellos marcas formales de esa situación que integramos hablantes y oyentes, es decir, del marco comunicativo (la 'enunciación'); la identificación de este tipo de rasgos lingüísticos (a veces, palabras concretas, pero otras veces, rasgos morfosintácticos) nos da información sobre los hablantes, su intención comunicativa o su actitud frente a los receptores o el propio mensaje. Utilizar la pragmática como marco teórico nos permite dar coherencia global a las investigaciones habituales de la teoría de la mente, pues podemos utilizar una teoría unificada para explicar la adecuada comprensión de todos los fenómenos de inferencia, como ironía, metáfora, inconveniencia, indiscreción o descortesía verbal, etc., evaluadas habitualmente por separado, mediante tareas de historias extrañas y falsas creencias (Gallardo, 2008: 29-30).

En este sentido, Cummings (2005) argumenta que los errores en la teoría de la mente de los autistas no son más que problemas pragmáticos; de este modo "autistic children's failure to treat other people as intentional agents is [...] not an explanation of their pragmatic deficits, but is itself a pragmatic deficit" (Cummings, 2008: 12).

A mediados del siglo XX, Chomsky, padre del modelo generativista, contribuyó con sus teorías gramaticales y sus teorías en torno a la capacidad innata para el 
lenguaje a revolucionar el panorama de la psicología y la neuropsicología abogando por la existencia de un dispositivo de adquisición del lenguaje (LAD -Language Acquisition Device) de base gramatical que se concebía como un órgano más de nuestro cerebro. Su teoría intentaba explicar y defender la idea de la existencia de unas pautas universales formales de adquisición del lenguaje en los niños. Su modelo generativo-transformacional ha sido la base de muchos estudios psicológicos centrados en el lenguaje no patológico y patológico. En relación con estos últimos se desarrollaron instrumentos de evaluación que analizaban los aspectos formales del lenguaje (fonológicos y gramaticales) y centraban la rehabilitación en ellos principalmente. Este modo de evaluación e intervención excesivamente formal y poco flexible descuidaba otros aspectos más centrados en la funcionalidad del lenguaje, los modos de comunicación e interacción del paciente con otros interlocutores; se parte de los datos reales que las personas proporcionan en cuanto a su conocimiento del lenguaje y su uso, y se tiene muy en cuenta los factores semánticos y también pragmáticos en la evaluación de los datos procedentes del ámbito clínico:

There may be a more illuminating way to explain why $[\ldots]$ to opt for a nongenerative framework. If I have an electrical problem with my car, I go to a car mechanic rather than a theoretical physicist. The physicist's information would be more scientifically correct, but for my purposes the intuitive practical knowledge of the mechanic is more useful. Salkie (1990: 95).

En general "el conjunto de las pruebas estandarizadas destaca por su incompetencia en la evaluación de las habilidades pragmáticas de un hablante" y por suerte "se ha pasado del trabajo de laboratorio en situaciones experimentales y estándares a promover la observación y la reflexión sobre las situaciones reales de comunicación (Garayzábal, 2004: 173), más complejas de analizar y evaluar dado que las variables que influyen son menos susceptibles de control (situación, contexto, interlocutor, las características psicológicas del propio paciente, entre otras). Este aspecto se desarrollará exhaustivamente en el apartado 5 que sigue a continuación.

Independientemente del marco teórico elegido por su adecuación a la explicación de los datos clínicos que manejemos, es un hecho que existen teorías dentro de cada marco que han pasado desapercibidas, o que resultan obsoletas dentro de la perspectiva lingüística actual, pero que cobran especial relevancia en el marco de las patologías linguiísticas. Mencionaremos aquí dos de ellas enmarcadas en el modelo cognitivista y que siguen siendo fuente de una crítica importante por parte de modelos formalistas. Nos referimos a la teoría de la gestalt y la teoría de la fonología natural.

La teoría de la gestalt se desarrolla en los años 20 del siglo XX y su base teórica se sustenta sobre la idea del todo unificado y de que el todo no es igual a las partes que lo componen. Las teorías gestálticas intentan describir cómo la gente tiende a agrupar los elementos (todos unificados) cuando se aplican determinados princi- 
pios. Se articula en torno a dos leyes, por un lado la ley de la figura/fondo según la cual tendemos a focalizar nuestra atención sobre un objeto o determinado grupo de objetos (figura) destacándolos del resto de los objetos que los envuelven (fondo); por otro lado la ley de la buena forma que nos permite ver los elementos como unidades significativas y coherentes; ésta última ley gira en torno a los siguientes principios: similitud o semejanza (relaciona elementos similares), proximidad (relaciona elementos cercanos), cierre (ignora intervalos vacíos para completar una representación), continuación (agrupa elementos de forma uniforme). Se supone que las personas perciben holísticamente su entorno y lo transforman en unidades significativas. Este entorno es de naturaleza diversa y afecta al lenguaje. Cuando no percibimos holísticamente los estímulos lingüísticos, nos quedamos en los detalles y no los integramos (recordemos la parábola del elefante), luego, no los otorgamos sentido, así el lenguaje se convierte en un lenguaje muy literal (tanto comprensiva como productivamente) no se comprenden las bromas, ni las ironías, ni las frases hechas y se describen al detalle aspectos que carecen de relevancia. Es lo que ocurre, por ejemplo, con los autistas o con las personas a afectadas por el síndrome de Williams, que atienden a las partes y no al todo y en la misma manera se comunican.

Como hemos dicho la gestalt se suele referir al todo, esto es, a sistemas y estructuras completas más que a prestar atención a los componentes más pequeños de un hecho o conducta determinados. De alguna manera parece que la mente del ser humano intenta encontrar patrones u organizaciones entre diferentes elementos y les otorga sentido, y eso constituye la base del aprendizaje.

Estas teorías, aunque han tenido su continuidad dentro del marco de la lingüística cognitiva (véase Cuenca y Hilferty, 1999) no han permeabilizado del todo en el mundo de la lingüística y menos aún lo han hecho en el campo de las alteraciones. A pesar de ello, existe un trabajo muy interesante en español publicado por la profesora Pérez Juliá (2002) que desarrolla la importancia de la lingüística perceptiva a la hora de analizar y describir las patologías del lenguaje.

Por lo que respecta a la fonología natural se trata de una teoría desarrollada por Stampe a finales de los años 70. Desde esta teoría se defiende el hecho de que los niños cuando comienzan a hablar llevan a cabo procesos de simplificación fonológica que van eliminándose a lo largo del desarrollo. Las dificultades que llevan a estos procesos de simplificación no se deben generalmente a problemas en la articulación de los sonidos, sino a la estructuración fonológica de las palabras. Explica gran parte de los procesos fonológicos de simplificación como resultado de las características físicas del aparato fonador y auditivo del hablante, aún no del todo maduro y, por tanto, limitador.

Si bien esta teoría sigue estando vigente en el ámbito psicolingüístico, tuvo una vida efímera en el campo de la lingüística (Gil, 2000; Hernando, 2007), no entendemos muy bien por qué; tal vez al relacionar los procesos fonológicos con 
las tendencias innatas y naturales de los hablantes y no centrarse en determinar las reglas que podrían constituir una teoría del lenguaje, la aproximación de la fonología natural era más psicológica que lingüística. No obstante, empíricamente puede demostrarse la validez de este modelo fonológico tanto a partir de datos de tipicidad como de anormalidad, por su prolongación en el tiempo de los procesos de simplificación fonológica en ciertas patologías. Sigue siendo un modelo explicativo muy válido y constituye una sólida base teórica con una inmediata aplicación práctica al servicio de la rehabilitación de trastornos fonológicos como las dislalias.

\section{Aspectos metodológicos en lingüística Clínica}

Entre los investigadores sociales no hay serias diferencias entre quienes observan sin pensar y quienes piensan sin observar; las diferencias más bien se refieren a qué clase de pensamiento, qué clase de observación y qué clases de vínculos, si es que hay alguno, existen entre ambas cosas (C. Wright Mills, apud Delgado y Gutiérrez, 2007: 69).

\subsection{Metodología cuantitativa y cualitativa para la recogida y análisis de datos lingüísticos}

El término metodología designa el modo en que enfocamos los problemas y buscamos las respuestas, en definitiva, cómo nos acercamos al problema. Para ello se tienen en cuenta dos perspectivas, la perspectiva metodológica cuantitativa y la cualitativa. Las distinciones metodológicas atienden a criterios de finalidad, diferentes de una disciplina a otra.

La metodología cuantitativa supone una recogida de datos fácilmente puntuable que suelen tener en cuenta el input y el output sin llegar a valorar los procesos que median entre uno y otro. Se trata de una metodología que desde la aplicación lingüística apenas se utiliza, pero es muy frecuente en el campo médico y psicológico.

Dentro de los métodos cuantitativos tal vez sea el método experimental el más utilizado. Éste método parte de la investigación de conjuntos de muestras diferentes de personas. Básicamente el objetivo último es comprender cómo funciona el ser humano, cómo somos capaces de actuar (verbalmente, psicológicamente, motóricamente, etc) y comprender esas actuaciones. Da por supuesto que todos estamos organizados de la misma manera y que actuamos según unos principios comunes que debemos conocer de modo que podamos precisar la conducta humana y poder identificar en qué difiere una persona de estos parámetros. Desde este paradigma se adopta una perspectiva positivista que consiste en generar datos y analizarlos estadísticamente. Los métodos cuantitativos enfatizan la fiabilidad de los datos, esto es, su consistencia. Tradicionalmente se ha considerado que los métodos cuantitativos, especialmente los experimentales, sientan las bases de la sistematicidad científica. 
Además de los métodos cuantitativos, disponemos también de métodos y técnicas cualitativas que son los que prevalecen en las ciencia sociales, por ende en Lingüística. Se toma en cuenta la perspectiva fenomenológica que favorece la generación y análisis de datos descriptivos y sigue una perspectiva integradora en un contexto naturalista (Iñiguez, 1999; Taylor y Bogdan, 2000; Delgado y Gutiérrez, 2007).

Ambos enfoques se aplican al campo de la investigación de las patologías del lenguaje y se complementan, si bien existe una clara inclinación actual dentro de este campo hacia las técnicas cualitativas cuyo propósito es su aplicación clínica. Un ejemplo claro lo tenemos en la revista American Journal of Speech-Language Pathology que en el no 12, volumen 2 del año 2003 dedicó un foro a la investigación cualitativa en el que escribieron autores de la talla de Damico y Simmons; Tetnowski y Franklin; Brinton y Fujiki; Culatta, Kovarsky, Theadore, Franklin y Timler. Del mismo modo, la importancia de los métodos cualitativos está reconocida desde hace casi dos décadas dentro del ámbito médico y de la salud, tradicionalmente cuantitativista (Conde, 2002; Amezcúa y Gálvez, 2002).

La complejidad que subyace al sistema de comunicación del ser humano obliga a prestar atención a las personas en contextos y situaciones concretas, por lo que el enfoque cualitativo cobra especial relevancia e interés al desarrollarse en contextos naturales o ecológicos y sociales, por ello son mucho más flexibles. En lingüística la información cualitativa es muy importante y los instrumentos que mejor nos permiten obtener esta información son las pruebas no estandarizadas que se articulan dentro del paradigma sociolingüístico y permiten analizar la producción comunicativa en situaciones naturales:

[El paradigma sociolingüístico] sostiene que la competencia comunicativa es situacional, interactiva, funcional y evolutiva. Analiza el lenguaje producido en situaciones naturales, en el propio contexto en que se producen y frente a los propios participantes comprometidos en tareas reales [...] Abarca tanto datos verbales como no verbales y contextuales (Soprano, 2001: 17-18).

Los principales métodos desarrollados con aplicación concreta en Lingüística Clínica son los que adoptan la perspectiva etnográfica e interaccional y el análisis del discurso y conversacional (Kirk y Miller, 1886; Codesido, 1997; Damico et al, 1999; Simmons-Mackie y Damico, 2001; Herbert et al, 2003; Perkins, 2005; Damico y Ball, 2008; Müller et al, 2008; Wilkinson, 2008).

Hablar de metodología y aspectos metodológicos supone responder a preguntas como: a) ¿Qué queremos ver?; b) ¿Cómo obtenemos los datos?; c) ¿Cómo los analizamos?; d) ¿De quién los obtendremos?; e) ¿Para qué los queremos? En términos generales la metodología cualitativa obtiene los datos de contextos naturales, parte de una conducta observable y a partir de estos datos empíricos se enuncian hipótesis, en lugar de obtener los datos para valorar teorías o modelos establecidos. 
Los datos se recogen en situaciones de interacción con otras personas y, aunque se siguen procedimientos rigurosos, estos no suelen estar estandarizados. Finalmente los datos obtenidos se someten a un detallado análisis. El acento de la metodología cualitativa recae en la validez de los datos, es decir, en la representación fehaciente e indiscutible de los datos analizados.

\subsection{Los datos lingüísticos}

Los datos lingüísticos van a ser la base sobre la cual podamos llegar a crear el perfil lingüístico de un hablante o de un conjunto de hablantes. Deberemos determinar qué aspectos de la lengua nos interesan y en cuáles debemos fijarnos. Estos se reducen a dos, aspectos formales y aspectos de la complejidad comunicativa, pueden ser descritos por separado o podemos estudiar complementariamente ambas dimensiones, formal y funcional, a la vez.

Si llevamos a cabo un trabajo de investigación podemos determinar con antelación el aspecto lingüístico que nos interesa y conforme a ello buscar personas que presenten dificultades en esos aspectos $u$ obtener un grupo de hablantes indeterminado, seleccionado por medio de una serie de criterios de homogenización de la muestra, sobre el que llevaremos a cabo la recogida de muestras de habla y nos fijaremos posteriormente en la descripción de los aspectos determinados inicialmente.

\subsection{Los datos lingüísticos. ¿De quién recabamos los datos?}

La toma de las muestras comunicativas requiere del acceso a personas. La determinación de perfiles lingüísticos patológicos que permitan el desarrollo de pruebas de evaluación, estandarizadas o no-estandarizadas, y el desarrollo de materiales lingüísticos que sirvan de herramientas eficaces al logopeda, vendrá determinado por los recursos humanos de que dispongamos o sobre los cuales queremos llevar a cabo la recogida de datos, lo que supone responder a la pregunta ¿De quién vamos a recabar los datos?

La respuesta obliga a contemplar como punto de partida principal cuatro variables importantes en relación con la selección de los participantes: la cantidad de personas, la edad, la naturaleza de los datos y su tipología; la elección dependerá de los objetivos de nuestro trabajo.

Otras variables que en un primer momento pueden resultar secundarias, aunque en un segundo momento cobran especial relevancia, son el sexo, el nivel sociocultural, el nivel educativo, la procedencia del hablante (raza y etnia) situaciones de bilingüismo (Moreno, 2005). Desde el ámbito de la logopedia también se resaltan ciertas variables que influyen en el posterior proceso de intervención y que, por supuesto, se sustentan en una descripción lingüística y sociolingüística del paciente (Cervera e Ygual, 2006). 
En relación con la cantidad debemos determinar si la recogida de datos procederá de una sola persona (estudio de caso) o de más (estudio de series de casos). Los estudios de casos son muy interesantes cuando la patología que presenta el paciente, y que compromete a su sistema lingüístico, tiene una incidencia muy baja. En estos casos resulta muy informativo cualquier tipo de descripción que contemple casos individuales. Cuando un déficit lingüístico es más frecuente, el estudio de caso suele diluirse más y no cobra tanta importancia. Un problema que plantean las descripciones de caso tiene que ver con la tipicidad de esos comportamientos lingüísticos descritos ¿hasta qué punto son indicativos de la tipicidad del comportamiento lingüístico de las personas?

El estudio de caso es una herramienta válida y está ampliamente aceptada en el ámbito de la neuropsicología. La suma de estudio de casos puede constituir una serie de casos en los que habría que establecer regularidades y puntos en común o diferencias entre ellos, lo que, por otro lado, permite llevar a cabo análisis contrastivos. Sin ir más lejos, el libro de Perkins y Howard (1995) es un estudio de casos en lingüística clínica, tal y como se indica en el propio título.

Por lo que respecta a la edad debemos observar si los datos que nos interesan proceden de la población infantil o adulta. En el primero de los casos han de tomarse en consideración conocimientos básicos en relación con el comportamiento lingüístico y comunicativo prototípico, tanto en la recogida como en el posterior análisis de los datos. Esto nos permite determinar la línea evolutiva de nuestro paciente su adecuación en un perfil de prototipicidad supuesto para su edad o en su distancia o inadecuación respecto de ese perfil. De este modo, no nos sirve el patrón adulto para analizar la competencia lingüística de un niño de ocho años con retraso del lenguaje, sino que habremos de remitirnos a los modelos de aprendizaje y adquisición adecuados a la edad del niño.

En el caso de un adulto deberemos obtener datos relacionados con su competencia y capacidad lingüística previa a su situación actual de déficit lingüísticocomunicativo y compararla con lo que se manifiesta en el momento de la recogida de información de datos de su lengua y su habla; se valorarán principalmente las capacidades que permanecen, las que están ausentes o las que están alteradas.

\subsection{Los datos lingüísticos: técnicas cualitativas para su recogida}

Una vez sabemos de quién vamos a obtener los datos existen varias procedimientos y herramientas para su recogida.

En primer lugar, los datos pueden obtenerse por medio de la simple observación de la conducta comunicativa (Milroy, 1987); la observación implica no llevar a cabo ningún tipo de manipulación de la situación; por ello es conveniente planificar y determinar previamente lo que queremos observar; si no sistematizamos previamente la observación nos resultará más complejo precisar y establecer los aspectos de 
relevancia que queramos encontrar una vez comience la situación de observación, i.e. determinado tipo de estructuras gramaticales inadecuadas, errores de la articulación o aspectos extralingüísticos como los gestos que apoyan la comunicación. En este sentido, las formas ecológicas de obtención de datos comunicativos favorecen el estudio de la dimensión pragmática y ponen de manifiesto las múltiples posibilidades a la hora de crear el perfil linguístico de los hablantes (Codesido, 2006). El procedimiento que se sigue es observar, registrar y analizar el comportamiento en el contexto.

La observación como técnica tiene algunos inconvenientes, como que en el momento de la observación no obtengamos los datos que queremos, que no sea suficiente el tiempo que le dedicamos, o que no sea el momento adecuado para el hablante, que por sus circunstancias personales puede estar cansado, nervioso. Si la observación implica a más de una persona, el número de variables que intervienen es mucho mayor y deberemos tener en cuenta, por ejemplo, que el problema sea de la misma naturaleza o si los interlocutores se conocen o no; en caso de conocerse, cómo es su relación (jerárquica, de iguales). Aunque en un primer momento los datos de la observación son cualitativos, los podemos cuantificar posteriormente.

También podemos recoger muestras de habla espontáneas por medio de entrevistas con el paciente o los pacientes. Las entrevistas pueden ser estructuradas o semiestructuradas. Es conveniente que en la entrevista las preguntas no sean cerradas (si/no), sino abiertas, dado que proporcionan más información.

Las entrevistas estructuradas están muy controladas, pretenden obtener los datos de la manera más precisa con el menor influjo de variables posible; se hace la pregunta y el paciente responde debiéndose ajustar a la pregunta, si no se atuviera a ésta el entrevistador lo guiará rápidamente a la estructura establecida.

En una entrevista semi-estructurada cabe la posibilidad de que el paciente divague sobre la pregunta o se pierda en explicaciones. El entrevistador puede realizar preguntas que inicialmente no estaban en el guión, pero que surgen a partir de la respuesta del paciente. Son entrevistas flexibles y muy dinámicas, aunque debemos asegurarnos de que los aspectos que queremos obtener aparezcan. Las entrevistas semi-estructuradas pueden derivar en grupos de discusión en los que pueden surgir aspectos relevantes para la recogida y posterior análisis de los datos.

Por medio de tareas específicas, semidirigidas o elicitadas, conseguimos también muestras de producciones orales, desde contar un cuento a recordar un suceso o una película, narrar una historia a partir de imágenes, comentar una noticia, entre otros.

Los cuestionarios constituyen otra técnica de recogida de datos, en este caso la información la obtenemos a través de la formulación de preguntas escritas a las que responde el propio paciente o personas de su entornos más cercano y que suele ser la familia. Tienen como propósito recoger información específica sobre el paciente. Cuando se trata de un adulto, siempre y cuando su comprensión y 
producción no se vea comprometida, es éste quien responde a las preguntas del cuestionario. En el caso de los niños son los padres o tutores quienes realizan la tarea de completamiento del cuestionario.

El registro de las respuestas se realiza a partir de afirmaciones o preguntas que el paciente o familiar debe intentar valorar en una escala numérica que refleja el grado en el que se manifiesta una determinada conducta lingüística (p.e. valore del 1 - poco frecuente- al 5 -muy frecuente-, si tiene problemas para expresar lo que quiere decir). Las respuestas pueden ser también de verdadero o falso, o de sí o no (p.e. me cuesta articular ciertos sonidos). Los cuestionarios no se consideran medidas válidas, pues la información que proporcionan es subjetiva, pero podemos obtener información de ellos. Codesido (2004) refleja el proceso de creación y análisis de un cuestionario dirigido a profesionales del ámbito logopédico para obtener información de los métodos diagnósticos y de evaluación en TEL.

\subsection{Los datos lingüísticos: su naturaleza}

La procedencia de los datos lingüísticos puede ser muy diversa y dependerá de nuestros objetivos determinar la naturaleza de estos.

La variable edad es determinante, como hemos podido observar anteriormente, y determina la primera gran selección en torno a la procedencia de los datos lingüísticos: población adulta o población infantil. Optar por un grupo u otro supone diferente variación en la naturaleza de los datos.

Cuando nos centramos en la recogida de datos procedentes de niños ¿lo haremos sobre población infantil con un desarrollo típico del lenguaje o con una población con alteraciones del lenguaje? En el primero de los casos, los datos que obtendremos permitirán analizar lo que es esperable que un niño a una determinada edad produzca y comprenda; crearíamos perfiles lingüísticos de tipicidad que servirían de referentes para poder analizar conductas lingüísticas anómalas. En el segundo de los casos, se abre un amplio abanico de etiologías diferentes. Podríamos tener en cuenta los siguientes aspectos:

1. Carácter primario o secundario de la alteración lingüística, esto es, el problema es específicamente lingüístico (dislalia, afasia infantil adquirida) o está derivado de otros problemas (discapacidad intelectual, TDAH -Trastorno por déficit de la atención e hiperactividad).

2. Causas del trastorno. Pueden ser causas orgánicas o funcionales. Las primeras tienen una razón genética, neurológica o anatómica (i.e. fisura palatina, labio leporino, disartia, afasias, sordera, síndrome de Down). Las segundas se refieren a aquellas que sin haber una causa orgánica afectan a la competencia lingüística, pero no impiden la comunicación (i.e. dislalia, retraso simple del lenguaje, TEL). 
3. Proceso afectado: comprensión o producción: En este caso los problemas residirían en la recepción del mensaje (dificultades de la audición más o menos severas) en la producción (i.e. afasia, TEL, disartia, disfluencias, desorden del lenguaje) o en ambas (i.e. algunos tipos de afasias).

4. Alteraciones en la capacidad intelectual o no.

5. Dificultades lingüísticas específicas de los niveles de análisis lingüístico: fónico (i.e. dislalia, laringectomía), gramatical (i.e. TEL, afasias), semántico (i.e. afasias, demencias tipo Alzheimer) o pragmático - discursivo y conversacional - (i.e. autismo, lesionados del hemisferio derecho).

La naturaleza de los datos es, pues, muy diversa. Las afasias y el trastorno específico del lenguaje han sido los trastornos que más se han estudiado en el ámbito de la logopedia, psicología, logopedia y lingüística clínica. Desde hace poco más de dos décadas se han hecho tímidas incursiones en otros problemas como queda reflejado en los manuales actuales de lingüística clínica (Ball et al, 2008; Cummings, 2008) aunque la hegemonía de las afasias sigue siendo difícil de deponer incluso hoy día. En España el escaso marco de estudios en lingüística clínica que existen se han fijado más en los aspectos de producción que de recepción y dentro de los primeros las afasias y la adquisición del lenguaje siguen siendo el centro predominante de la investigación. Poco a poco empiezan a apuntar otras tendencias en la investigación que incluyen, por ejemplo, el trastorno por déficit de la atención, síndromes de dificultades de aprendizaje no verbal y demencias tipo Alzheimer.

\subsection{Los datos lingüísticos: herramientas para su análisis}

La recogida de muestras comunicativas puede realizarse por medio de grabaciones de audio, video o recogida manual de información. Sin duda las audio-video grabaciones son la mejor manera de poder registrar los datos reduciendo el riego de pérdida de información relevante.

Las grabaciones en audio suelen ser suficiente, salvo que queramos obtener información relacionada a la interacción comunicativa en sí misma donde aspectos relacionados con gestos, contacto ocular, etc. son muy importantes, en este caso las grabaciones en video son muy pertinentes y recomendables.

Independientemente del soporte que utilicemos lo que vamos a conseguir es la creación de un corpus cuyo análisis dependerá de las variables que queramos estudiar (análisis de errores fónicos, sintácticos, semánticos, pragmáticos). El corpus en sí mismo ya constituye una herramienta en bruto.

¿Qué podemos hacer con un corpus? Con los datos recogidos en corpus podemos llevar a cabo diferentes tipos de análisis.

A) Podemos recurrir a las transcripciones. Cualquier tipo de transcripción requiere ser de gran precisión. Si nos queremos centrar en cuestiones de pronunciación, 
esto es, analizar el nivel fónico utilizaremos la trascripción fonética y fonológica para lo que recurriremos a las normas de la IPA (1999) o a su página web (http:// www.langsci.ucl.ac.uk/ipa/); podemos utilizar el Alfabeto de la Revista Española de Filología, para la trascripción de sonidos y fonemas específicos de la lengua española (véase punto 4.1. de este trabajo). Con la trascripción fonético-fonológica daremos cuenta, por ejemplo, de errores del habla o de alteraciones del lenguaje. En mi opinión, deberemos evitar en la medida de lo posible transcribir aquel material lingüístico que no vayamos a necesitar, especialmente porque el proceso de trascripción es largo y tedioso.

En la transcripción ortográfica se emplea la ortografía convencional para la representación de las palabra. Suele tener un carácter más pragmático donde importan los turnos y lo que cada hablante dice de manera que podamos registrar escrupulosa y correctamente la grabación realizada. En este tipo de transcripciones, normalmente es recomendable alinear en filas numeradas cada emisión realizada e identificar al comienzo de cada intervención con una sigla a la persona que habla. Las tomas de turnos, las pausas, movimientos de cabeza, contacto ocular, suspiros, toses, dudas, pronunciaciones poco claras, velocidad, énfasis, son ejemplos de elementos susceptibles de ser descritos ortográficamente. Existen muchas convenciones para la transcripción ortográfica, en España tenemos los criterios del corpus PERLA (Gallardo, 2003; Garayzábal, 2005; Moreno, 2007), pero otros criterios de transcripción se pueden encontrar en Jefferson (1989) Psatas (1995) o Bloomer, Griffiths y Merrison (2005):

$\begin{array}{ll}0546 \mathrm{P} . & \text { yo/ si se lo digo a mis padres } \uparrow / / \text { lo(s) convenceré } ~ \\ 0547 \mathrm{~B} . & \text { sí sí } \\ 0548 \mathrm{P} . & \text { ahora cuando llegue/ se lo digo } \\ 0549 \mathrm{~B} . & \text { sí sí } \\ \text { 0550 P. } & \text { *(l’)*han dicho mis padres que no me dejarían pe ro } \rightarrow \text { / no me } \\ & \text { dejan } \downarrow / / \text { pero yo voy a in sis tir/ *(yovoya)* isistir } \\ 0551 \mathrm{~B} . & \text { asistir } \\ 0552 \mathrm{P} . & \text { mmucho mucho ma[ch]- } \\ 0553 \mathrm{~B} . & \text { [ch] } \\ 0554 \mathrm{P} . & \text { más y todo lo que pueda/ para conseguirlo } \\ 0555 \mathrm{~B} . & \text { para conseguirlo (CANTURREANDo)/ ¿tienes hora? (Garayzábal, } \\ & \text { 2005: } 84 \text { ). }\end{array}$

B) Otra herramienta es el etiquetado de corpus. El etiquetado permite llevar a cabo análisis de diferentes tipos. Podemos etiquetar morfemas, lexemas y estructuras. Así, podemos ver cuántas veces aparece en la muestra recogida en el corpus el morfema que indica tiempo indefinido, del modo indicativo de verbos de la primera conjugación. Para ello etiquetaremos previamente los lemas del verbo y sus morfema. Un etiquetado léxico, por ejemplo, nos permite ver la frecuencia de una palabra, 
su co-ocurrencia, su distribución. Un etiquetado gramatical facilitará información en torno a las diferentes combinaciones estructurales dentro de un sintagma dado, o en una oración con verbo transitivo, etc.

Por un lado, existen etiquetas ya hechas, como las de EAGLES - Expert Advisory Group on Language Engineering Standards - (1996), que son de carácter sintácticomorfológico y que constituyen una representación estándar lingüísticamente neutral respecto de la información lingüística; por otro lado existe la posibilidad de crear un propio sistema de etiquetado, por ejemplo el corpus CHIEDE - Corpus de Habla Infantil Espontánea del Español- (González-Ledesma y Garrote, 2007; Garrote y Guirao, 2008) o el corpus C-ORAL-ROM (Sandoval, et al, 2005; Moreno y Girao, 2006; Alcántara, 2007). Otro conocido corpus, CHILDES, combina ambos tipos de etiquetas: http://childes.psy.cmu.edu/data/manual/.

La etiquetación de corpus suele realizarse en SGML (Standard Generalized Markup Language) o en XML (Extensible Markup Language) y la forma de etiquetar es: $<$ Nombre $>$ o $<$ NMS $>$ (nombre masculino singular) o <lema $>$

C) La Longitud Media de Emisión -LME (Brown, 1973) es una técnica de análisis morfológico que permite registrar el crecimiento lingüístico. Las puntuaciones que aporta permiten interpretar las emisiones lingüísticas en términos evolutivos.

D) El LARSP- Language Assessment Remediation and Screening Procedure (Crystal, Fletcher y Garman, 1976) constituye el primer gran registro de perfiles lingüísticos; permite trazar perfiles sobre la base de características gramaticales. Parte de la recogida de muestras de habla que han de transcribirse en emisiones individuales que permitirán completar datos referidos a siete estadios del desarrollo sintáctico relacionados con el tipo de oraciones, nivel de cláusulas y frases y nivel de palabra. En la hoja de registro del perfil se irá atribuyendo un nivel con respecto a una edad y al final se registra claramente dónde existen problemas y dónde no en relación con las estructuras de la lengua.

E) El Protocolo Pragmático (Prutting y Kirchner, 1983) funciona como un listado de control de ciertas conductas que suelen producirse durante la grabación. Contiene 30 parámetros pragmáticos que se agrupan en torno a tres grandes aspectos: verbal, paralingüístico y no verbal. Se registran los datos en términos de adecuación o inadecuación de la conducta pragmática.

F) El PCA (Penn, 1988) es otra herramienta de análisis pragmático que tiene en cuenta aspectos tales como la respuesta al interlocutor, el contenido semántico, la cohesión, la fluidez, comunicación no verbal y sensibilidad sociolingüística.

El análisis de los datos puede ser numérico (llegando a posibilitar un análisis estadístico de los datos) o no numérico. En el primer caso, llegar a conclusiones es mucho más rápido, dado que los datos numéricos son más directos a la hora de interpretarlos, pero debemos saber interpretarlos y muchas veces se requieren de complejos análisis estadísticos que suelen estar fuera del conocimiento de un lingüista. En el caso de que manejemos datos no numéricos, los resultados son menos concluyentes y más resbaladizos. 


\subsection{Los datos linguíísticos: su análisis}

Cuando recogemos datos hay un propósito inicial que nos guía en la toma de decisiones en relación a la edad y el número de participantes, procedencia del material lingüístico, método más conveniente de recogida de información y datos concretos que queremos obtener y posteriormente analizar.

Hemos comentado más arriba que los enfoques principales en los que se mueve la lingüística clínica son los formalistas y los funcionalistas. En el primero de los casos se parte de "hipótesis de la teoría lingüística [...] se establece una modelización del lenguaje, un simulacro sobre su composicionalidad, estructura y procesamiento" (Cabré y Lorente, 2003: 2), esto es, se parte de una teoría general del lenguaje humano como capacidad del hombre y los datos sirven para corroborar o falsar las hipótesis de partida. Se parte, en definitiva, de supuestos a priori en los que se trata de probar ideas (modelo hipotético-deductivo). En el segundo de los casos se parte de los datos empíricos y su análisis se encamina hacia la creación, perfeccionamiento o comprobación de alguna teoría teniendo en cuenta la faceta social y comunicativa del lenguaje. Por ello se cuenta con datos reales de actuación lingüística y cuantos más, mejor, para poder llevar a cabo generalizaciones sobre el lenguaje (modelo inductivo).

Los estudios en nuestro país tienen un enfoque fundamentalmente pragmático y menos formal, prueba de ello es que existen pruebas de creación de perfiles lingüísticos semánticos y gramaticales de amplio renombre y validez en el mundo anglosajón que no han llegado a nuestro país y las que han llegado no se han adaptado a las lenguas nacionales o no se han seguido criterios de uso, sino normativos, que nos obligan a relativizar su validez.

\subsection{Los datos lingüísticos. ¿Qué podemos hacer con ellos?}

El resultado final del tratamiento de una alteración por parte del profesional especializado es su mejoría o su restablecimiento. No resulta difícil pensar que para corregir un problema del habla, de la lengua o de la comunicación, hay que evaluar y para evaluar hay que analizar y para analizar hay que describir. Por tanto el punto de partida es la descripción.

Una vez recogidos los datos el paso siguiente es describir lo que en ellos hay, organizando y sistematizando la realidad lingüística que tenemos frente a nosotros. Así, con estos datos podemos crear perfiles lingüísticos que podremos contrastar con otros para poder llevar a cabo modestas generalizaciones sobre el lenguaje.

A partir de los perfiles lingüísticos podemos crear taxonomías de rasgos lingüísticos patológicos, viendo dentro de una misma patología lo que es común y lo que es diferente y, tal vez, poder crear criterios diagnósticos de base lingüística. 
Sobre los perfiles y taxonomías de rasgos lingüísticos podemos aportar datos relevantes para el desarrollo de pruebas para la evaluación del lenguaje de base lingüística, esto es, obtenida sobre muestras de habla reales recogidas en contextos naturales y no creadas sobre una gramática ideal, pero irreal.

Con el análisis de los datos, la creación de perfiles lingüísticos y la elaboración de taxonomías lingüísticas podemos y debemos elaborar materiales lingüísticos de apoyo específico y general que sirvan de herramienta a los logopedas a la hora de rehabilitar un trastorno determinado.

Por último, con los datos obtenidos cualitativamente y exhaustivamente analizados y categorizados podemos llevar a cabo investigaciones interesantes en torno a esta exclusiva capacidad humana, entendiendo su funcionamiento, entendiendo cómo funcionan las lenguas, sosteniendo teorías o desbancándolas, apoyando o no la universalidad lingüística.

\section{Referencias bibliográficas}

AA.VV. (2003): "Special Forum on Qualitative Research", American Journal of SpeechLanguage Pathology, $\mathrm{n}^{\circ} 12$ (2), págs. 130-188.

AA.VV. (2007): Actas del XXII Congreso Internacional de la Asociación de Jóvenes Lingüistas, vol. 18. Sevilla, Asociación de Jóvenes Lingüistas (en prensa).

Alfabeto fonético de la RFE, Revista de Filología Española, 2 (1915), págs. 374-376.

Alonso-Cortés, A. (2002): Lingüística. Madrid, Cátedra.

Amezcua, M. y A. Gálvez (2002): "Los modos de análisis en investigación cualitativa en salud: perspectiva crítica y reflexiones en voz alta", Revista Española de Salud Pública, 76, págs. 423-436.

Ball, M. y R. Kent (1987): Editorial de Clinical Linguistics and Phonetics, 1, págs. 1-5.

Ball, M. (1992): The clinician's guide to linguistic profiling of language impairment. Kibworth, Far Communications.

Ball, M. (1993): Phonetics for Speech Pathology. Londres, Taylor y Francis.

Ball, M., Perkins, M., Müller, N. y S. Howard (eds.) (2008): The handbook of clinical lingistics. Londres, Blackwell Publishing.

Benveniste, E. (1977): Problemas de lingüística general, II. México, Siglo XXI.

Black, M. y S. Chiat (2008): "Cognition, Semantics and Syntax". En Ball, M., Perkins, M., Müller, N. y S. Howard (eds.), págs. 290-309.

Bloomer, A., Griffiths, P. y A. Merrison (2005): Introducing language in use. A coursebook. Londres, Routledge.

Bray, M.; Ross, A. y C. Todd (2006): Speech and Language: Clinical Process and Practice. Londres, Whurr.

Brinton, B. y M. Fujiki (2003): "Blending Quantitative and Qualitative Methods in Language Research and Intervention", American Journal of Speech-Language Pathology, 12 (2), págs. 165-171.

Brown, R. (1973): A first language. The early stages. Massachusetts, Harward University Press.

Brumfitt, S. (2004): Innovations in Professional Education for Speech and Language Therapy. Londres, Whurr. 
Bryan, K. (1994): The Right hemisphere Battery. Londres, Whurr Publications.

Cabré, M. T. y M. Lorente (2003): "Panorama de los paradigmas en lingüística". En Estany, A. (coord.) (2003), págs. 1-26.

Caplan, D. (1987): Neurolinguistics and linguistic aphasiology. Cambridge, Cambridge University Press.

Cervera, J. F. y A. Ygual (2006): “Intervención logopédica en los niveles de la lengua”. En Garayzábal, E. (ed.), págs. 423-497.

CHIEDE: http://www.lllf.uam.es/ESP/proyectos/chiede.htm

Codesido, A. I. (1997): “Aproximación desde la etnografía del habla al proceso de enseñanza-aprendizaje de una lengua materna”, Reale, 7, págs. 9-18.

Codesido, A. I. (1998): "Las discapacidades comunicativas en edad infantil: algunas implicaciones teóricas desde la lingüística clínica", Revista de Logopedia, Foniatría y Audiología, vol. XVIII; nº 4, págs. 194-204.

Codesido, A. I. (2004): "Revisión del cuestionario Trastornos Específico del Lenguaje: métodos diagnósticos y evaluación”. En Villayandre, M. (coord.), págs. 635-648.

Codesido, A. I. (2006): "Evaluación no estandarizada de patologías del lenguaje en niños castellanohablantes: el análisis lingüístico de algunas pruebas". En Gallardo, B., Hernández, C. y V. Moreno (eds.), págs. 39-55.

Conde, F. (2002): "Encuentros y desencuentros entre la perspectiva cualitativa y la cuantitativa en la historia de la medicina", Revista Española de Salud Pública, 76, págs. 395-408.

Cresti, E. y M. Moglia (eds.) (2005): C-ORAL-ROM Integrated Reference Corpora for Spoken Romance Languages. Amsterdam, John Benjamins.

Crystal, D. (1980): A Dictionary of Linguistics and Phonetics. Londres, Blackwell Publishers. [vers. Española: Diccionario de lingüística Española. Barcelona, Octaedro Universidad. Barcelona].

Crystal, D. (1981): Clinical Linguistics. Londres, Edward Arnold.

Crystal, D. (1984): Linguistic encounters with language handicap. Londres, Edward Arnold.

Crystal, D., Fletcher, P. y M. Garman (1989): The Grammatical Analysis of Language Disability. Londres, Cole y Whurr.

Cuenca, M. J. y J. Hilferty (1999): Introducción a la lingüística cognitiva. Barcelona, Ariel.

Culatta, B., Kovarsky, D., Theadore, G., Franklin, A. y G. Timler (2003): “Quantitative and Qualitative Documentation of Early Literacy Instruction”, American Journal of SpeechLanguage Pathology, 12 (2), págs. 172-188.

Cummings, L. (2005): Pragmatics. A multidisciplinary perspective. Edimburgo, Edimburg University Press.

Cummings, L. (2008): Clinical linguistics. Edimburgo, Edimburg University Press.

Damico, J., Oelschlaeger, M. y N. Simmons-Mackie (1999): "Qualitative methods in aphasia research: conversation analysis", Aphasiology, vol. 13 (9-11), págs. 667-679.

Damico, J. y N. Simmons-Mackie (2003): "Qualitative Research and Speech-Language Pathology: A Tutorial for the Clinical Realm”, American Journal of Speech-Language Pathology, 12 (2), págs. 131-143.

Damico, J. y M. Ball (2008): Clinical Sociolinguistics. En Ball, M., Perkins, M., Müller, N. y S. Howard (eds.), págs. 107-130. 
Delgado, J. M. y J. Gutiérrez (coords.) (2007): Métodos y técnicas cualitativas de investigación en ciencias sociales. Madrid, Síntesis.

Duckworth, M., Allen, G., Hardcastle, W. y M. Ball (1990): "Extensión to the Internactional Phonetic Alphabet for the transcription of atypical speech", Clinical Linguistics and Phonetics, 4, págs. 273-280.

EAGLES (1996): Synopsis and comparisonof morphosyntactic phenomena encoded in lexicons and corpora. A common proposal and applications to european languages. Pisa: ILC-CNR.

Estany, A. (coord.) (2003): Enciclopedia Iberoamericana de Filosofía. Vol. Ciencias exactas, naturales y sociales. Madrid, Consejo Superior de Investigaciones Científicas.

Fava, E. (Ed.) (2002): Clinical Linguistics: theory and applications in speech pathology and therapy. Series IV Current Issues in Linguistic Theory. Amsterdam/Filadelfia, John Benjamins.

Fernández, M. (1984): "El carácter de la ciencia lingüística”, Verba, 11, págs. 129-156.

Fernández, M. (1998): "El papel de la teoría y de la aplicación en la construcción de disciplinas lingüísticas. El caso de la Lingüística Clínica y áreas conexas”, Revista Española de Lingüística, 28(2), págs. 389-419.

Gallardo, B. (2003): "La elaboración del corpus PerLA (Percepción, Lenguaje y Afasia)". En Fernández Pérez, M. (dir.): Xornadas de Lingüística Aplicada á Linguaxe Infantil e á Afásica. Santiago de Compostela, Universidad de Santiago de Compostela (sin publicación).

Gallardo, B. (2006): "Más allá de las palabras y la estructura. Las categorías del componente pragmático". En Garayzábal, E. (ed.), págs. 81-196.

Gallardo, B. (2008): "Las huellas lingüísticas de la teoría de la mente: intersubjetividad y enunciación en el trastorno por déficit de atención/hiperactividad", Revista de Neurología, 46 (Supl 1), págs. 29-35.

Gallardo, B., Hernández, C. y V. Moreno (eds.) (2006): Lingüística clínica y neuropsicología cognitiva. Actas del I Congreso de Lingüística clínica. Valencia, Universidad.

Garayzábal, E. (2004): "Las alteraciones del lenguaje desde una perspectiva linguiística: el estado de la cuestión”, Revista de Logopedia, Foniatría y Audiología, vol. 24(4), págs. 169-177.

Garayzábal, E. (2005): El síndrome de Williams. Materiales y análisis pragmático. Valencia, Publicaciones de la Universidad de Valencia.

Garayzábal, E. (2006a): “ [el péðo de san đóke no tjéne đáßo] ¿Rasgos distintivos o dislalia? La lingüística y la logopedia: fronteras disciplinarias y disciplinas complementarias”. En Garayzábal, E. (2006) (ed.), págs. 21-79.

Garayzábal, E. (2006b): “Adquisición y pruebas de evaluación fonológica: una revisión desde la Lingüística”, Revista Virtual de Estudios da Linguagem-ReVEL, año 4; no 7.

Garayzábal, E. (ed.) (2006): Lingüística Clínica y Logopedia. Madrid, Antonio Machado Ediciones.

Garayzábal, E. y P. Otero (2005): "Psicolingüística, Neurolingüística, Logopedia y Lingüística Clínica: Juntos sí, pero no revueltos”, Filología y Lingüística, XXXI (1), págs. 163-185.

Garayzábal, E. y M. Capó (2006): “El papel del lingüista en las pruebas de evaluación del lenguaje: el componente fonológico y gramatical”. En Gallardo, B., Hernández, C. y V. Moreno (eds.), págs. 111-121. 
Garman, M. y S. Edwards (1995): “Syntactic assessment of expressive language”. En Grundy, K. (ed) Linguistics in Clinical Practice. Londres, Taylor y Francis, págs. 92-117.

Garrote, M. y J. M. Guirao (2008): “CHIEDE: corpus de habla infantil espontánea del español”, Procesamiento del lenguaje Natural, 41, págs. 297-298.

Gil, J. (ed.) (2000): Panorama de la fonología española actual. Madrid, Arco libros.

González-Ledesma, A. y M. Garrote (2007): "Los marcadores discursivos en CHIEDE, un corpus de habla infantil espontánea”. En AA.VV. (coords.) (en prensa).

Grunwell, P. (1988): “Clinical linguistics, retrospect and prospect”. En Grunwell, P. (ed.) Applied linguistics in Society. Londres, Warwick, págs. 36-50.

Gutiérrez, I. (1997): Introducción a la historia de la logopedia. Madrid, Narcea.

Herbert, R., Best, W., Hickin, J., Howard, D. y F. Osborne (2003): “Combining lexical and interactional approaches to therapy for word finding deficits in aphasia", Aphasiology, Vol. 17 (12), págs. 1163-1186.

Hernández, C. y E. Serra (coords.) (2002): Estudios de Lingüística Clínica. Valencia, Nau Llibres.

Hernando, L. A. (2007): “Aspectos teóricos de los modelos fonológicos”, Dicenda. Cuadernos de Filología Hispánica, 25, págs. 105-123.

HMSO (1972): Speech Therapy Services, Report of the Committee of Inquiry. HMSO. Londres.

Íñiguez, L. (1999): “Investigación y evaluación cualitativa”, Atención Primaria, 23 (8), págs. 496-502.

IPA (1999): Handbook of the International Phonetic Association: A Guide to the Use of the International Phonetic Alphabet. Cambridge, Cambridge University Press. http://www. langsci.ucl.ac.uk/ipa/index.html)

Jefferson, G. (1989): "Preliminary notes on a possible metric which provides for a "standard maximum" silence of aproximately one second in conversation". En Roger, D. y P. Bull (eds.), págs. 166-196.

Kawaguchi, Y., Zaima, S. y T. Takagaki (eds.) (2006): Spoken Language Corpus and Linguistic Informatics. Amsterdam, John Benjamins.

Kirk, J. y M. Miller (1986): Reliability and validity in qualitative research. California, Sage publications.

Levin, B. y H. Rappaport Hovav (2005): Argument realization. Cambridge, Cambridge University Press.

Lleal, C. (coord.) (2002): Historia de la lengua española. Barcelona, Ediciones de la Universidad de Barcelona.

Love, R. y W. Webb (1986): Neurology for the speech-language pathologist. Tenesee, Butterworth Publishers.

Marantz, A., Miyashita, Y. y W. O’Neil (eds.) (2000): Image, language, brain. Massachusetts, MIT Press.

Milroy, L. (1987): Observing and analysing natural language: A critical account of sociolinguistic method. Oxford, Blackwell.

Moreno, V. (2007): "La obtención y análisis de datos orales en lingüística clínica", Oralia, 10, págs. 213-231.

Moreno, F. (2005): Principios de sociolingüística y sociología del lenguaje. Madrid, Ariel.

Moreno, A., Madrid, G., Alcántara, M., Gonzalez, A., Guirao, J. M. y R. Torre (2005): “The Spanish Corpus”. En Cresti, E. y M. Moglia (eds.), págs. 135-163. 
Moreno, A., y J. M. Guirao (2006): "Morpho-syntactic Tagging of the Spanish C-ORALROM Corpus: Methodology, Tools and Evaluation". En Kawaguchi, Y., Zaima, S. y T. Takagaki (eds.), págs. 199-218.

Moreno-Torres, I. (2004): Lingüística para logopedas. Valencia, Ediciones Aljibe.

Müller, N., Guendouzi, J. y B. Wilson (2008): "Discourse Analysis and Communication Impairment”. En Ball, M., Perkins, M., Müller, N. y S. Howard (eds.), págs. 3-32.

Navarro, T. (1966-67) "El alfabeto fonético de la Revista de Filología Española", Anuario de Letras (Universidad Nacional Autónoma de México), 6, págs. 5-10.

Obler, L. y K. Gjerlow (1999): Language and the Brain. Cambridge, Cambridge University Press.

Penke, M. (2008): “Morphology and language disorders”. En Ball, M., Perkins, M., Müller, N. y S. Howard (eds.), págs. 212-228.

Penn, C. (1988): "The profiling of syntax and pragmatics in aphasia", Clinical Linguistics and phonetics, 2, págs. 179-207.

Pérez Juliá, M. (2002): "Lingüística Perceptiva y patologías del lenguaje”. En Hernández, C. y E. Serra (coords.), págs. 99-129.

Perkins, M. y S. Howard (eds.) (1995): Case Studies in Clinical Linguistics. Londres, Whurr Publishers.

Perkins, M. (2005): “Clinical pragmatics: an emergentist perspective”, Clinical Linguistics and Phonetics, 19 (5), págs. 363-366.

Perkins, M. (2007): Pragmatic Impairment. Cambridge, Cambridge University Press.

Prutting, C. y D. Kirchner (1987): "A clinical appraisal of the pragmatic aspects of language”, Journal of Speech and Hearing Disorders, 52, págs. 105-119.

Psatas, G. (1995): Conversation análisis: the study of talk-interaction. Londres, Thousand Oaks.

Roger, D. y P. Bull (eds.) (1989): Conversation. Clevendon, Multilingual Matters.

Rojo, G. (2002): "Sobre la linguiística basada en el análisis de corpus", Hizkuntza-corpusak. Oraina eta geroa, 10 (24/25) págs. 1-17.

Salkie, R. (1990): The Chomsky Update: Linguistics and politics. Londres, Unwin Hyman.

Simmons-Mackie, N. y J. Damico (2003): "Intervention outcomes: A clinical Application of qualitative methods", Topics in Language Disorders, 22 (1), págs. 21-36.

Simmons-Mackie, N. y J. Damico (2003): "Contributions of Qualitative Research to the Knowledge Base of Normal Communication", American Journal of Speech-Language Pathology, 12 (2) págs. 144-154.

Soprano, A. M. (2001): La “hora de juego" lingüística. Buenos Aires, Lumière.

Stampe, D. (1979): A Dissertation on Natural Phonology. Nueva York, Garland Publishing Co.

Taylor, S. J. y R. Bogdan (2000): Introducción a los métodos cualitativos. Barcelona, Paidos.

Tetnowski, J. y T. Franklin (2003): “Qualitative Research: Implications for Description and Assessment”, American Journal of Speech-Language Pathology, 12 (2), págs. 155-164.

Villayandre, M. (coord.) (2004): Actas del V Congreso de Lingüística General. Madrid, Arco Libros.

Wilkinson, R. (2008): “Conversation Analysis and Communication Disorders”. En Ball, M., Perkins, M., Müller, N. y S. Howard (eds.), págs. 92-107. 